\title{
Productivity and Competitiveness: The Case of Football Teams Playing in the UEFA Champions League
}

\author{
By Manuel Espitia-Escuer* \\ Lucia Isabel Garcia-Cebrian
}

\begin{abstract}
The purpose of this study is to evaluate the competitive situation of the UEFA Champions League in relation to other entertainment alternatives. As tools of analysis, Malmquist indices for the football teams that have participated in the UEFA Champions League among the years 2003-2011 will be calculated. The Malmquist index measures the change in productivity whereas the efficiency ratios used for the calculation of the former were found by applying a Data Envelopment Analysis (DEA). The relationship between productivity and competitiveness in an economic sector is as follows: an increase in productivity allows the remuneration of the factors to be increased without having to raise the price of the product offered. The UEFA Champions League may see its competitiveness threatened in relation to other entertainment alternatives, because participating teams do not show a clear increase in productivity.
\end{abstract}

Keywords: Data envelopment analysis, Football, Malmquist, Productivity.

\section{Introduction}

In this study we calculate and analyze the changes in productivity experienced by football teams participating in the UEFA Champions League from 2003-2011. The theoretical framework that has been adopted and which justifies this study is the management theory. According to this theory, the significance of an organization's productivity ratio transcends the mere productive function and has strategic implications. It indicates the percentage by which the remuneration of the factors of production can be increased, without the need of increasing the price of the goods or services to the consumers and therefore, without altering the profitability of the organization or its competitiveness within its sector.

In previous studies, Blass (1992) and Mazur (1994) have studied the productivity of the team members of sports clubs to relate it to their salaries; however, the approach of this study differs in two aspects.

First, the productivity ratio used is the Malmquist index, which incorporates information on all of the firm's productive resources in its calculation and therefore, may be considered an index of total factor

* Professor, University of Zaragoza, Spain.

$\dagger$ Lecturer, University of Zaragoza, Spain. 
productivity which overcomes the difficulties of the interpretation of partial indexes.

Second, this study evaluates the productivity of the football teams that have participated in the UEFA Champions League during the period defined by the study for the purpose of evaluating how competitive they are in relation to their competitors, which in broad terms would be other entertainment options. This last statement requires further development, since football clubs have to deal with sports rivalry and sport competition which should not be confused with competition in the economic sense.

Both the competitors and the objectives of the football clubs are different depending on whether the teams are considered individually or in the context of the tournament in which they are involved. From an individual point of view, a team faces a rival in each game it plays with the objective of defeating the opponent and by accumulating victories, winning the tournament in question.

On the other hand, each competition (such as the UEFA Champions League, World Cup and the National Leagues) has a governing board whose involvement goes beyond merely establishing the rules of the game, since it can intervene in negotiations regarding, for instance, the scheduling of the matches or gambling.

Therefore, strictly from a sports perspective, each individual team employs its resources and uses the tactics it has developed to compete against its rivals in the leagues and tournaments in which the team participates. At the same time, each sport championship can be considered an organization whose governing boards act and represent all participating teams as a whole, as they are in charge of negotiating aspects that are of common interest to all of the clubs. These negotiations will have repercussions on the revenues that each club receives, given that they include aspects such as television broadcast rights.

However, these revenues will also depend on the product/service that the teams offer, which in this case is the sports event itself. Demand will be generated if the potential consumers receive sufficient utility to merit the price they must pay to attend the game. Football, as a spectacle for spectators, must compete with all those sectors related with entertainment, which may include other sporting events or alternatives further removed from a product/service point of view, such as the cinema or the theater. This is where the consideration of productivity can contribute to improving the competitiveness, in the economic sense, of the football teams. Only increases in the productivity of the factors employed by the teams can justify an increase in the retribution of those factors; otherwise, an increase in the remuneration of the factors of production would translate to an increase in the price of the sports event and its competitiveness would suffer. The idea of the relationship between the use of productive resources and competitiveness in football teams is also present in Pestana Barros et al. (2014).

In short, each team has a sports objective, which is to defeat its rivals. However, all of those rivals then group together in a governing body for each 
one of the tournaments and from an economic point of view, the profitability of the individual teams is both influenced and protected by the negotiations undertaken by the governing body of the tournament or league in which it participates.

This study takes as a premise that the UEFA, as the organizer of the Champions League, should ensure that the product/service being offered is competitive, in other words that it is sufficiently attractive to generate demand. Therefore, it should be concerned with increasing the productivity of the participating teams by, for example, establishing rules that reward the most productive teams.

The Malmquist index is the measure of the change in productivity used in this study. The basis for its calculation is the efficiency indices resulting from the application of Data Envelopment Analysis (DEA) for the teams that make up the sample. The Malmquist index takes into account all of the production factors used by the organization, therefore the conclusions that can be drawn overcome the limitations of single factor productivity indices. On the other hand, calculating the Malmquist index using the DEA method allows considering the change in productivity as the result of two different effects: efficiency change and technical change (Grosskopf 1993).

The efficiency ratios must refer to the productive process being evaluated. In a simplified form and following the postulates of Schofield (1988), Carmichael and Thomas (1995) and Carmichael et al. (2000) for sports teams, the productive process to create the product/service offered by the football clubs is composed by two phases. The first is the training responsible for the physical conditioning of the players, where the tactics that the team will use during the games is decided. The second phase involves the games themselves, where the teams face their rivals and where the final product of these types of organizations, related to sports entertainment, is produced. At the same time these two phases are linked, since the product of the first phase (the plays made during the game), would be the input to the second.

The present study is structured in the following manner. Next, the paper reviews the theoretical relationship among productivity, competitiveness and its application to the case of football teams. Subsequently, it shows the methodology used to calculate the changes in productivity using the Malmquist index and the representative variables used for the football team's productive process. In the last two sections the authors present the results and the conclusions.

\section{Application of the Theory of the Firm to Football Clubs}

Classical economic theory uses isoquant to represent organizations' production systems. Assuming perfect information, freedom to enter/exit the industry and the absence of influence in setting market prices, organizations that constitute a sector will launch the amount of product demanded by consumers on the market at a price set through the interaction of supply and 
demand. On an individual level, each firm, in its quest to maximize profit, launches the amount of product that equals price and marginal cost, uses a combination of factors situated on the isoquant and earns no extraordinary profits.

However, empirical evidence shows that the model used in the classical economic theory depicting firms as profit maximizing agents with the restriction of the initial endowment of resources is too simplistic. Besides, the non-compliance with the underlying hypothesis of the classical economic theory's model has opened up new lines of research.

Imperfect information and the bounded rationality may result in the choice of a combination of factors that produce the output that is above the isoquant. The firm's technical system is represented by its possibilities of production, which show all the amounts of final products that could be produced by a given combination of the factors; the isoquant only represents the maximum amount of these possibilities of production. In reality all of them could actually occur although, from a conceptual point of view, they imply a departure from the isoquant, which Farrell (1957) defines as inefficiency and supposes a utilization of resources in greater quantities than what is strictly necessary. Leibenstein (1962) attributes the same meaning to the term when raising the importance of the loss of efficiency due not to imperfections of the market, but rather to a wrong allocation of resources within the firm.

The view of both authors varies greatly from the consideration of firms as "black boxes" that is characteristic of the economic theory and gives more relevance to the role of managers in the internal administration of the firms. Firms are considered complex organizations where members are specialized in their tasks. Managers, through their knowledge, the instructions they give and the incentives they establish are the ones that have the responsibility of situating the firm on the isoquant as far as production is concerned. A tool available to help managers achieve this are the classical management approaches since, as Chiavenato (1999) emphasizes, both Taylor and Fayol were concerned with increasing the efficiency of the firms through the rationalization of the workers' tasks and the organization and application of scientific management principles, respectively.

However, the efficient use of resources in production, that is, the absence of waste, which conceptually would be represented by the choice of a combination of inputs on the isoquant, is not an end in itself. Given that organizations develop products and services with the idea of launching them in the market and competing with the other organizations of the sector, producing a product efficiently results in cost savings that contribute to the firm's competitiveness and long-term survival. If empirical evidence shows that organizations choose combinations of factors that are above the isoquant then the productivity ratio, which is the ratio of the amount of product obtained to the amount of resources employed, will not be the same for all firms. The productivity ratio is, once again, another concept that relates production with competitiveness and therefore could serve as guidance for managerial decisionmaking. 
Productivity is a measure for the evaluation of the productive activity of the organizations that relates the amount of product obtained to the resources employed; it is a concept that is limited to the productive area of the organization and therefore based on the ideas of inputs, outputs and the production function. Besides, only increases in productivity can justify an increase in the retribution of the factors of production, without a corresponding increase in the price of the product. In other words, an increase in the retribution of the factors that is not accompanied by an increase in productivity would mean an increase in the price of the product that would negatively affect the competitiveness of the firm.

It is of interest to analyze the productivity changes of football teams due to the relationship between this concept and the competitiveness of the organizations. Competitiveness is relevant to football clubs, because they operate in a competitive environment composed by, not only the teams that dispute the tournament, but also other entertainment options that the fans could choose to attend if the competition does not meet their expectations or if they consider the price to be excessive.

There is no consensus in the literature as to whether the objective pursued by sports teams is the maximization of economic performance or the maximization of sports results, as can be seen in the studies of Fort and Quirk (1995), Szymanski (2003), Sandy et al. (2004), Fort (2006), Késenne (2007), Garcia del Barrio and Szymanski (2009). The perspective adopted in this paper is the following: regardless of the lack of consensus in the literature regarding the football clubs objectives, economic profit must certainly be taken into account and can provide information about the management of the clubs ${ }^{1}$. Therefore, even in the event that football clubs are not considered for-profit organizations whose objective is profit maximization, they should be aware of the opportunities they have to increase it, the repercussions that their decisions have on it and the risks they are exposed to that could decrease it. In short, all of the stated above regarding efficiency, productivity and competitiveness applies to them. Therefore, it is necessary to reflect about the nature of the product of a football team and what activities are needed to produce it. That would allow the representative variables of the production function to be established, the isoquant to be used as a theoretical reference tool and the productivity to be calculated as an approximation to the competitive situation within the sector.

The football team's product is the show they offer during each game or throughout a tournament and the sports results they achieve. For this, they need an opponent with which to dispute the victory in accordance with the rules and scoring system established for each competition. Therefore, the teams do not compete among themselves for what would be the equivalent of a market, but rather for the sports result; the victory in the game or the overall tournament (composed of the sum of the victories in the individual games that make up that tournament). Consequently, the true competitor for the market is not the sports

${ }^{1}$ For example, Szymanski (1998) evaluates, among other variables, the economic profit of the European football club Manchester United, linking revenues and costs to sports results. 
opponent. Therefore, if the games are the productive activity of the football teams and the sports results are the product, then the analysis of their productivity must focus exclusively on the plays made.

As in all organizations, the profit of football teams is the difference between revenues and expenses. The first depend on the demand for the "product" of the teams, which are the games and tournaments played and come from the sales of tickets and passes, broadcasting rights, advertising, sponsorship, the sale of merchandise such as t-shirts, etc. Revenues are influenced by the sports results of the team, the existence of other entertainment alternatives and the price at which the product is offered. Expenses are made up of things such as personnel, facilities, travel, transportation, etc. A reduction in the expenses increases the profits. Given that a portion of the costs are generated in the production function, efficiency, understood as the choice of a combination of resources situated on the isoquant and therefore as the absence of waste, contributes to reducing them. Furthermore, theoretically, the change in productivity is a reference for determining the increase in the remuneration of the factors of production that the club can absorb without altering its selling price thereby maintaining its competitiveness $^{2}$.

\section{Methodology and Variables}

This study follows the proposals of Grosskopf (1993) to calculate the changes in productivity of the football teams that participated in the UEFA Champions League. This author argues that her approach differs from that of other authors, since it allows for inefficiency in the organizations, meaning that the combination of the factors used to produce the product may not be on the isoquant. In consequence, the increase in productivity is not the equivalent of technical progress. The approach of Grosskopf (1993) belongs to the frontier models of efficiency calculation initiated by Farrell (1957) who considers deviations from the isoquant to be inefficiency. Farrell (1957) also proposes to measure efficiency as the distance existing between the combinations of factors actually used by the organization under study and that are situated on the isoquant ${ }^{3}$. Furthermore, the proposal of Farrell (1957) to calculate the efficiency of an organization consists of starting from the observations of the inputs actually consumed and the outputs obtained from a homogeneous sample and

\footnotetext{
${ }^{2}$ This idea should be completed with the price elasticity of the demand function for the entertainment that the football teams offer in comparison to other entertainment options. That is, only in the case that the demand for football was inelastic the increase in price, due either to an increase in the price of the inputs or for any other reason, would have little effect on the quantity demanded by consumers.

${ }^{3}$ The normal two-dimensional representation of the isoquant corresponds to production processes that use two inputs and obtain the same output. However, the concept can be generalized for multi-output and multi-input production processes and the Formulae presented and used in this paper also allow for it.
} 
take the envelopment of actual data as the isoquant - thus the denomination "frontier" by which the methodology proposed by this author is known.

In this context, Grosskopf (1993) defines the increase in productivity as the net change in the amount of output produced due to changes in the efficiency and to technical change. She also states that changes in efficiency are modifications over time in the distance between the observations of an organization's inputs/outputs and the representative isoquant of its production technology. On the other hand, technical change could be interpreted as changes over time in the position of the isoquant with respect to the origin of the coordinate system. The definition of these two concepts can also be found in Thiry and Tulkens (1989).

In order to measure the changes in the productivity of an organization, Grosskopf (1993) proposes the Malmquist productivity index as a starting point, as Caves et al. (1982). Under the assumption that the organizations can be inefficient and this inefficiency will be calculated by frontier methods, observations of the amounts of inputs consumed and the products produced are needed for each of the organizations in the sample for two consecutive periods. This information will be used in the following Formula (1) to calculate the Malmquist productivity index for each organization:

$$
\mathbf{m}_{\mathrm{i}}^{t}=\frac{\lambda_{\mathrm{i}}^{t}\left(\mathbf{x}_{\mathrm{i}}^{t+1}, \mathbf{y}_{\mathrm{i}}^{t+1}\right)}{\lambda_{\mathrm{i}}^{t}\left(\mathbf{x}_{\mathrm{i}}^{t}, \mathbf{y}_{\mathrm{i}}^{t}\right)}
$$

where, the subscript $\mathrm{i}$ refers to the organization being studied and the superscript $t$ or $t+1$ refers to the period from which the information was taken. In greater detail:

\begin{tabular}{|c|c|}
\hline $\mathbf{m}_{\mathbf{i}}^{t}:$ & $\begin{array}{l}\text { is the Malmquist productivity index of organization } \mathrm{i} \text { based on } \\
\text { the isoquant corresponding to period } t \text {. }\end{array}$ \\
\hline & $\begin{array}{l}\text { is the vector of the quantities of inputs consumed by } \\
\text { organization I in period } t \text {. }\end{array}$ \\
\hline $\mathrm{y}_{\mathrm{i}}^{t}$ : & $\begin{array}{l}\text { is the vector of the outputs obtained by organization } \mathrm{i} \text { in period } \\
t \text {. }\end{array}$ \\
\hline$\lambda_{\mathrm{i}}^{t}\left(\mathbf{x}_{\mathrm{i}}^{t}, \mathbf{y}_{\mathrm{i}}^{t}\right)$ & $\begin{array}{l}\text { is the efficiency value of organization } \mathrm{i} \text { in period } t \text { taking the } \\
\text { technology of period } t \text { as a reference, that is the distance that } \\
\text { separates the combination of factors that organization i used in } \\
\text { period } t \text { from the isoquant or frontier, calculated using the } \\
\text { information of the entire sample for period } t \text {. }\end{array}$ \\
\hline$\lambda_{\mathrm{i}}^{t}\left(\mathbf{x}_{\mathrm{i}}^{t+1}, \mathbf{y}_{\mathrm{i}}^{t+1}\right)$ & $\begin{array}{l}\text { is the efficiency that organization i would have achieved if its } \\
\text { consumption of factors and its production for period } t+1 \text { were } \\
\text { valued with respect to the isoquant corresponding to period } t \text {. }\end{array}$ \\
\hline
\end{tabular}


Measuring the increase in the productivity of an organization Grosskopf (1993) proposes using the geometric average of the two Malmquist indexes for the consecutive period's $t$ and $t+1$ by calculating the following expression:

$$
\mathbf{M}_{\mathrm{i}}\left(\mathbf{x}_{\mathrm{i}}^{t+1}, \mathbf{y}_{\mathrm{i}}^{t+1}, \mathbf{x}_{\mathrm{i}}^{t}, \mathbf{y}_{\mathrm{i}}^{t}\right)=\left[\frac{\lambda_{\mathrm{i}}^{t}\left(\mathbf{x}_{\mathrm{i}}^{t+1}, \mathbf{y}_{\mathrm{i}}^{t+1}\right)}{\lambda_{\mathrm{i}}^{t}\left(\mathbf{x}_{\mathrm{i}}^{t}, \mathbf{y}_{\mathrm{i}}^{t}\right)} * \frac{\lambda_{\mathrm{i}}^{t+1}\left(\mathbf{x}_{\mathrm{i}}^{t+1}, \mathbf{y}_{\mathrm{i}}^{t+1}\right)}{\lambda_{\mathrm{i}}^{t+1}\left(\mathbf{x}_{\mathrm{i}}^{t}, \mathbf{y t}_{\mathrm{i}}^{t}\right)}\right]^{1 / 2}
$$

This can be re-written in the following manner:

$$
\mathbf{M}_{\mathrm{i}}\left(\mathbf{x}_{\mathrm{i}}^{t+1}, \mathbf{y}_{\mathrm{i}}^{t+1}, \mathbf{x}_{\mathrm{i}}^{t}, \mathbf{y}_{\mathrm{i}}^{t}\right)=\frac{\lambda_{\mathrm{i}}^{t+1}\left(\mathbf{x}_{\mathrm{i}}^{t+1}, \mathbf{y}_{\mathrm{i}}^{t+1}\right)}{\lambda_{\mathrm{i}}^{t}\left(\mathbf{x}_{\mathrm{i}}^{t}, \mathbf{y}_{\mathrm{i}}^{t}\right)} *\left[\frac{\lambda_{\mathrm{i}}^{t}\left(\mathbf{x}_{\mathrm{i}}^{t+1}, \mathbf{y}_{\mathrm{i}}^{t+1}\right)}{\lambda_{\mathrm{i}}^{t+1}\left(\mathbf{x}_{\mathrm{i}}^{t+1}, \mathbf{y}_{\mathrm{i}}^{t+1}\right)} * \frac{\lambda_{\mathrm{i}}^{t}\left(\mathbf{x}_{\mathrm{i}}^{t}, \mathbf{y}_{\mathrm{i}}^{t}\right)}{\lambda_{\mathrm{i}}^{t+1}\left(\mathbf{x}_{\mathrm{i}}^{t}, \mathbf{y}_{\mathrm{i}}^{t}\right)}\right]^{1 / 2}
$$

According to Grosskopf (1993), the Malmquist index is made up of two components. Breaking it down as shown in (3) allows them both to be calculated: the term outside of the brackets measures the efficiency change, while the bracketed term measures the technical change.

The way to calculate the efficiency values that form part of the Malmquist index proposed by Grosskopf (1993) remain to be determined.

Among the possible frontier approaches, this study has opted for DEA. It is not necessary to specify the form of the production function to apply DEA; however, it is based on the concept of process as the transformation of productive resources into final products for the determination of the variables that intervene in the calculation. The efficiency value of the units that compose the study sample is the ratio found by solving the following linear programming problem ${ }^{4}$ :

$$
\begin{array}{cc}
\text { Minimize } & \lambda_{\mathbf{I}} \\
\text { s.t. } \quad \lambda_{\mathbf{i}}^{*} \mathbf{x} & \geq \mathbf{u}^{*} \mathbf{X} \\
\mathbf{y} & \leq \mathbf{u} * \mathbf{Y} \\
\mathbf{u} & \in \mathbf{R}^{+}
\end{array}
$$

where,

$\lambda_{\mathrm{i}}$ : is the efficiency ratio found by solving the problem.

$\mathbf{x}_{\mathbf{i}}$ : is the vector of the amounts of input used by unit $i$.

$\mathbf{y}_{\mathbf{i}}$ : is the vector of the amounts of output obtained by unit $\mathrm{i}$.

$\mathbf{X}$ : is the matrix of the amounts of input used by the units of the sample.

$\mathbf{Y}$ : is the matrix of the amounts of output obtained by the units of the sample.

$\mathbf{u}$ : is the vector of the coefficients from solving the problem.

\footnotetext{
${ }^{4}$ In the notation of this problem superscripts denoting the period of reference are not used, because in its original Formulation DEA uses the sample data referring to only one period. Therefore, the efficiency ratio for each organization is calculated by taking the data of the consumption of the factors, the production and the isoquant with respect to which it is calculated for the same period.
} 
The formulation of the problem that has been presented assumes constant returns to scale ${ }^{5}$. An input orientation has been adopted whereby $\lambda_{i}$ is interpreted as the proportion by which the amounts of all productive resources employed by the unit under analysis must be reduced to situate it on the isoquant or frontier. Therefore, those units in the sample whose $\lambda_{i}$ is equal to unity will be classified as efficient, while those which have a $\lambda_{i}$ ratio value below one will be classified as inefficient.

Going back to the Malmquist index, this can show values lower than, higher than or equal to one. If an organization's Malmquist index is below one, the interpretation is that the organization has lowered its productivity between the two periods taken in consideration. If the productivity has increased the index will be higher than one and if the productivity has not changed the index will be equal to one. Each of these three possibilities can be the result of the combination of different values of the change in efficiency and technical change, which can take on values lower than, higher than or equal to one.

A value for the change in efficiency less than one means that the efficiency of the organization under study has diminished over time because it shows a lower value in period $t+1$ with respect to period $t$; the interpretation is the opposite where the value is greater than one and a ratio equal to one means that there has been no change in efficiency.

If a technical change shows a value lower than one it means that the isoquant that represents technology for period $t+1$ is farther from the origin of the coordinate system than in the preceding period, thus indicating that there has been a technical regression. It is also possible to show a value greater than unity, which would have the opposite interpretation and a value equal to one would indicate that there has been no technical change.

This paper focuses on the calculation and implications of the changes in the productivity of the football teams that have participated in the UEFA

\footnotetext{
${ }^{5}$ DEA also allows the calculation of the organization's efficiency ratio under the assumption of variable returns to scale. Given that, one of the advantages of DEA is that it does not require the specification of the production function, it seems coherent not to make assumptions concerning the returns to scale that the production process of the sample under study could show. This affirmation is not in contradiction with the possibilities of calculation that DEA offers: if the efficiency ratio is calculated under the assumption of constant returns to scale, what is known as a global technical efficiency is obtained, which measures inefficiency caused by both the waste of resources in production and the wrong choice of the size of the organization. The calculation of the efficiency ratio under the hypothesis of variable returns to scale eliminates the influence of this second factor and reveals the value of the so-called pure technical efficiency, which evaluates exclusively the waste of resources; the ratio of global technical efficiency to pure technical efficiency is the efficiency of scale, which measures the loss of efficiency due to the wrong choice of the size of the organization. Consequently, in this paper, calculating DEA under the assumption of constant returns to scale does not mean that the technology used by football clubs does not show variable returns, rather that the efficiency ratios that will be calculated to be used in the calculation of the Malmquist index include both the effects of the proper use of productive resources and the choice of the size of the organization.
} 
Champions League from 2003 to $2011^{6}$. This is not the only competition in which they participate, so their entire "production" which would include consumed resources and obtained sport results in national championships, is not taken into account in the input and output vectors. This could be seen as a limitation of the study however it also has the advantage that all of the teams that play in the UEFA Champions League have had to be placed among the top positions of their domestic competition in the previous season. This makes the sample more homogenous and the homogeneity of the sample units is one of the requirements for the correct application of DEA in the calculation of the efficiency ratios.

As for the output variable, that is, the variable that represents the success of the teams in the tournament in which they participate, it is important to emphasize that the UEFA Champions League is a knockout tournament; therefore, what is important is qualifying for the successive phases and in case of qualifying for the final, winning it. It is common for studies of the efficiency of football teams to use the points earned during the tournament ${ }^{7}$ or the number of goals scored ${ }^{8}$ as variables. However, neither of these two variables guarantees that the teams that obtain the highest values achieve a better classification in the UEFA Champions League. The UEFA Champions League's group system makes it possible for teams to advance to the following stage having earned fewer points than others that fail to advance only, because these played in a group where the combination of victories was less favorable to them.

On the other hand, a higher number of goals scored does not mean better sports results, as the number of goals does not guarantee victory. Scoring more goals than the opponent does provide the victory in one game. But a big difference between goals scored and goals conceded for the whole tournament can be the result of only one or a few won games with a big difference between these two variables, showing loses in the remainder games. So a big difference between scored and conceded goals through the whole tournament not always correspond with good sports results.

Taking into account the previous considerations, this study proposes the number of games played as the variable that best represents the success of the teams in UEFA Champions League. This output variable has the inconvenience that it takes the same value for the winner as for the runner-up, even though the winner is obviously more successful.

Concerning inputs to be considered in the production function for football teams, literature shows no agreement. One group of authors takes expenses as a

\footnotetext{
${ }^{6}$ Productivity of football teams has been calculated for national championships by Guzman and Morrow (2007), Espitia-Escuer and Garcia-Cebrian (2008), Douvis and Pestana-Barros (2008), Jardin (2010) for instance.

${ }^{7}$ Dawson et al. (2000), Haas (2003a, 2003b), Gonzalez-Gomez and Picazo-Tadeo (2010) use this output variable, although transformed or in combination with other complementary variables.

${ }^{8}$ Carmichael et al. (2000) use the difference between goals scored and goals conceded as output when specifying their production function and Bosca et al. (2009) state that the number of goals is a simple variable to measure the production of the football teams.
} 
variable representative of the consumed resources. Examples of this line are Haas (2003a, 2003b), Haas et al. (2004) and Guzman (2006). Nevertheless, Sexton et al. (1986) warn about the risk of confusing technical and price efficiency and recommend using variables measured in physical units. Also from a more general point of view, Border (2004) analyzes the Cobb-Douglas function and shows that prices should not be included in a production function. Authors that follow this suggestion in the case of football teams are EspitiaEscuer and Garcia-Cebrian (2008) and Bosca et al. (2009). In both papers input variables are plays made during games in line with the work of Carmichael et al. (2000).

The present article can be framed in this second group as the players that participate, as representatives of labor force and the plays made during the games are taken as the factors of production. The number of players that each team uses during the tournament is taken as the representative variable of the first. It can be argued that not all of the players are of the same quality and this will have an influence on the efficiency. However, quality is a concept that refers to the product offered on the market by an organization and not to the factors used in its production. The characteristics of the resources used in a production process will have an influence on the quality of the product, but those differences are precisely the ones that could explain the differences in the levels of efficiency achieved by the organizations included in the study ${ }^{9}$.

With regards to the plays made, the players make both offensive and defensive plays during the game, however only the offensive plays contribute to the victory. There are several justifications for making this affirmation.

First, in the extreme case in which a team only defends, it would not score any goals and therefore the best result it could achieve would be a scoreless tie, never a victory. On the other hand, the team executes defensive plays to offset the actions of the opposing team and in the representation of productive processes by isoquants, which is what DEA estimates, actions taken to adapt to the environment are never to be considered inputs ${ }^{10}$.

Finally, the defensive plays made by the opposing team could be considered, as they impede an offensive play from becoming a positive sports result. However, defensive plays from the rival cannot be considered factors of production for the team whose efficiency is being calculated. To do so would violate a condition considered as such: the quantity and use of the productive resources must be under the control of the firm. The team under study has no control over the defensive plays made by its opponent. Furthermore, continuing with the application of the characteristics of manufacturing to football teams,

\footnotetext{
${ }^{9}$ Golany and Roll (1989) recommend distinguishing between the factors of production and the variables that explain the differences detected in the efficiency values achieved by the organizations in the study.

10 For example, the chemical industry obtains products following the chemical Formulae, which would be the equivalent of the isoquant. However, the companies must also make efforts to comply with environmental laws or face restrictions to exploiting deposits which means additional effort, but is not reflected in their production function. Similarly, in manufacturing and in services, advertising could also be considered an activity to counter or anticipate, the actions of competitors and again it is not considered a productive resource.
} 
the manufacturer should take the amount of product actually sold by the firm as the output value, since sales are what generate profits and sales may differ from production due to poor forecasting by the company or the activity of competitors and these circumstances are not reflected in the isoquant. In the case of a football team, the difference between the sports results that it could achieve through its offensive plays and the results actually achieved, are due to the defensive plays of the opponent and therefore should not appear as inputs in the representation of the isoquant.

In conclusion, for this study, in addition to the team's offensive plays, the minutes of possession and shots taken have been chosen as representative variables of the resources employed in the game. The defensive plays made, either by the team or by its opponent, would be taken as explicative variables of efficiency, as proposed by Golany and Roll (1989) ${ }^{11}$. Given that for this study the production function only contemplates one output and that output is the number of games played during the UEFA Champions League competition, an input orientation was seen to be more appropriate for the calculation of the efficiency ratios. It makes more sense to recommend reductions in the consumption of inputs than to increase the output, since the latter would imply that inefficient teams should increase the number of games they play, when in fact the values that this variable can take on are set by the competition rules themselves.

All the variables representing the football team's production process used in this study have been obtained from the OptaSports database ${ }^{12}$. The calculations have been made using the total of each team's values for each of the seasons analyzed. The descriptive statistics of the variables used are shown in Table 1.

\section{Results}

The samples for which the changes in productivity have been calculated in this study are the football teams that played the UEFA Champions League for the seasons among 2003-2011. As shown in Formula (3), to calculate the Malmquist index, the efficiency ratios of each team are needed for two consecutive seasons. They are calculated from the input and output data, both for the team and for the total sample. Since the teams that compete in the UEFA Champions League change from year to year, the calculations were done as follows: the sample used for the year in question is composed by all the teams that participated in the competition, regardless of whether or not they

\footnotetext{
${ }^{11}$ Guzman (2006) also calculates and analyzes the productivity of football teams using the Malmquist index, however the inputs used are personnel costs and general expenses and the output, revenues. Sexton et al. (1986) recommend the use of variables measured in physical units, therefore excluding the remuneration of the factors, so as not to confuse the values of technical efficiency with price efficiency.

12 OptaSports is a private international company who provides information about teams participating in national and international football championships. Its web site is www.optasports.com.
} 
continued in the following season. However, the Malmquist index was only calculated for those teams that played at least two consecutive seasons and therefore it was possible to obtain all of the terms that are used in the Formula (3). Table 2 shows the results obtained.

Table 1. Descriptive Statistics of the Variables Used

\begin{tabular}{|c|c|c|c|c|c|c|}
\hline \multicolumn{2}{|c|}{ Analyzed seasons } & \multicolumn{4}{|c|}{ Input variables } & \multirow{3}{*}{$\begin{array}{c}\text { Output variable } \\
\text { Games played } \\
13\end{array}$} \\
\hline & & $\begin{array}{c}\text { Offensive } \\
\text { plays }\end{array}$ & \begin{tabular}{|c|}
$\begin{array}{c}\text { Number of } \\
\text { players }\end{array}$ \\
\end{tabular} & $\begin{array}{l}\text { Minutes of } \\
\text { possession }\end{array}$ & \begin{tabular}{|c|}
$\begin{array}{c}\text { Number of } \\
\text { shots }\end{array}$ \\
\end{tabular} & \\
\hline \multirow[t]{4}{*}{$2003 / 2004$} & Maximum & 1,444 & 25 & 364 & 181 & \\
\hline & Minimum & 587 & 17 & 143 & 53 & 6 \\
\hline & Average & 842.25 & 21.00 & 217.69 & 100.28 & 7.81 \\
\hline & Std. Dev. & 263.89 & 1.94 & 66.81 & 37.93 & 2.24 \\
\hline \multirow[t]{4}{*}{$2004 / 2005$} & Maximum & 1,504 & 27 & 375 & 162 & 13 \\
\hline & Minimum & 572 & 18 & 118 & 46 & 6 \\
\hline & Average & 848.56 & 21.38 & 206.88 & 99.72 & 7.81 \\
\hline & Std. Dev. & 262.16 & 2.27 & 67.54 & 37.86 & 2.24 \\
\hline \multirow[t]{4}{*}{$2005 / 2006$} & Maximum & 1,630 & 28 & 388 & 217 & 13 \\
\hline & Minimum & 612 & 16 & 131 & 51 & 6 \\
\hline & Average & 894.41 & 21.47 & 199.09 & 103.28 & 7.81 \\
\hline & Std. Dev. & 276.99 & 2.75 & 66.33 & 41.42 & 2.24 \\
\hline \multirow[t]{4}{*}{$2006 / 2007$} & Maximum & 1,465 & 30 & 328 & 203 & 13 \\
\hline & Minimum & 632 & 17 & 128 & 50 & 6 \\
\hline & Average & 910.59 & 22.31 & 194.84 & 104.91 & 7.81 \\
\hline & Std. Dev. & 251.46 & 2.55 & 59.80 & 40.50 & 2.24 \\
\hline \multirow[t]{4}{*}{$2007 / 2008$} & Maximum & 1,559 & 27 & 400 & 216 & 13 \\
\hline & Minimum & 658 & 16 & 126 & 44 & 6 \\
\hline & Average & 920.97 & 22.06 & 203.13 & 107.34 & 7.81 \\
\hline & Std. Dev. & 271.86 & 2.30 & 71.41 & 45.59 & 2.24 \\
\hline \multirow[t]{4}{*}{$2008 / 2009$} & Maximum & 1,531 & 25 & 428 & 227 & 13 \\
\hline & Minimum & 608 & 17 & 117 & 49 & 6 \\
\hline & Average & 918.44 & 21.22 & 197.16 & 104.47 & 7.81 \\
\hline & Std. Dev. & 262.36 & 2.13 & 76.47 & 45.19 & 2.24 \\
\hline \multirow[t]{4}{*}{$2009 / 2010$} & Maximum & 1,470 & 30 & 446 & 204 & 13 \\
\hline & Minimum & 612 & 17 & 116 & 34 & 6 \\
\hline & Average & 875.22 & 21.47 & 195.34 & 102.84 & 7.81 \\
\hline & Std. Dev. & 262.43 & 2.83 & 80.41 & 44.63 & 2.24 \\
\hline \multirow[t]{4}{*}{ 2010/2011 } & Maximum & 1,639 & 29 & 501 & 221 & 13 \\
\hline & Minimum & 673 & 17 & 119 & 46 & 6 \\
\hline & Average & 966.41 & 22.28 & 204.94 & 105.78 & 7.81 \\
\hline & Std. Dev. & 279.30 & 3.10 & 84.45 & 46.38 & 2.24 \\
\hline
\end{tabular}

Source: Authors' estimations.

It should be stressed that for each one of the seasons in the study, Table 2 shows the value of the change in the productivity of the football teams, with respect to the previous season, as measured by the Malmquist index. Furthermore, for each one of the values of the Malmquist index the values of its two components, efficiency change and technical change, are also shown. On the other hand, the blank cells in Table 2 represent situations in which it is impossible to calculate the Malmquist index corresponding to a given team; either because that team did not participate in the UEFA Champions League in 
that or the previous season. Finally, the last row of Table 2 shows the average values for each column, that is, the average of the Malmquist index and its two components for each season.

Focusing on the average productivity change in each of the seasons analyzed, it should be emphasized that there are increases in only three of them and by very small amounts (2004/2005, 2008/2009 and 2009/2010). Season $2006 / 2007$ showed no change over the previous year and in the rest decreased, with the decline in season 2010/2011 being especially noteworthy.

In the three seasons in which there was an increase in productivity on average, all of the teams experienced technical progress. With regards to the average changes in efficiency, in the seasons 2004/2005 and 2009/2010 there was a decrease in efficiency that was offset by technological progress and in 2008/2009 there was no change. Also, in these three seasons different cases regarding the evolution of efficiency can be observed if the teams are taken individually: there are some that increased, while others decreased and among the latter, some compensated the decrease with technical progress to the extent that they showed an overall increase in productivity.

In season 2006/2007 the average productivity did not change with regard to the previous season and also, on average, it can be seen that the decrease in efficiency is compensated by technological progress. With regard to the situation of the individual teams participating in the UEFA Champions League during that season, the majority experienced technical progress; however, this was not accompanied by an increase in efficiency in all cases. Among those that decreased efficiency predominated those that did not offset their decrease in efficiency with technical progress and therefore showed an overall decline in productivity. On the contrary, for the teams that suffered a technical regression in season 2006/2007, the evolution of their productivity coincides with that of their efficiency, i.e. those that increased their efficiency, also increased their productivity and vice versa.

In the rest of the seasons analyzed, on average the teams participating in the UEFA Champions League decreased their productivity and although they increased their average efficiency, it was not enough to compensate their technical regression. In season 2010/2011, all of the participating teams experienced a technical regression and of those that increased their efficiency, only two increased their productivity (Milan AC and Real Madrid). In the 2005/2006 season only one team (PSV Eindhoven) showed neither technical progress nor regression nor did its efficiency change, consequently its productivity remained unchanged. The rest experienced technical regression, however the majority of them showed an increase in efficiency, this compensated the technical regression and their productivity increased. Finally, in the season 2007/2008, only five teams did not experience technical regression. Two of them (Celtic and Liverpool) showed no change, nor did they vary their efficiency, therefore their productivity remained unchanged. 
Table 2. Malmquist Index Values by Season for the Teams Participating in the UEFA Champions League

\begin{tabular}{|c|c|c|c|c|c|c|c|c|c|c|c|c|c|c|c|c|c|c|c|c|c|}
\hline & \multicolumn{3}{|c|}{$\begin{array}{c}2004 / 2005 \text { over } \\
2003 / 2004\end{array}$} & \multicolumn{3}{|c|}{$\begin{array}{l}\text { 2005/2006 over } \\
2004 / 2005\end{array}$} & \multicolumn{3}{|c|}{$\begin{array}{c}\text { 2006/2007 over } \\
\text { 2005/2006 }\end{array}$} & \multicolumn{3}{|c|}{$\begin{array}{c}\text { 2007/2008 over } \\
\text { 2006/2007 }\end{array}$} & \multicolumn{3}{|c|}{$\begin{array}{c}\text { 2008/2009 over } \\
2007 / 2008\end{array}$} & \multicolumn{3}{|c|}{$\begin{array}{c}2009 / 2010 \text { over } \\
\text { 2008/2009 }\end{array}$} & \multicolumn{3}{|c|}{$\begin{array}{c}2010 / 2011 \text { over } \\
2009 / 2010\end{array}$} \\
\hline & \begin{tabular}{l|l}
1 \\
\end{tabular} & 2 & 3 & \begin{tabular}{l|l}
1 \\
\end{tabular} & 2 & 3 & \begin{tabular}{l|l}
1 \\
\end{tabular} & 2 & 3 & 1 & 2 & 3 & \begin{tabular}{l|l|}
1 & \\
\end{tabular} & \begin{tabular}{|l|}
2 \\
\end{tabular} & 3 & 1 & 2 & 3 & 1 & 2 & 3 \\
\hline AC Roma & & & & & & & & & & 1.0828 & \begin{tabular}{|l|}
0.9108 \\
\end{tabular} & 0.9862 & \begin{tabular}{|l|}
1.0000 \\
\end{tabular} & \begin{tabular}{|l|}
1.0098 \\
\end{tabular} & \begin{tabular}{|l|}
1.0098 \\
\end{tabular} & & & & & & \\
\hline Ajax & 0.9978 & 1.0266 & 1.0243 & 1.0103 & 0.9584 & \begin{tabular}{|l|}
0.9682 \\
\end{tabular} & & & & & & & & & & & & & & & \\
\hline Arsenal & 0.9985 & 1.0240 & 1.0225 & 1.0565 & 0.9816 & \begin{tabular}{|l|}
1.0371 \\
\end{tabular} & 0.9056 & 0.9920 & 0.8984 & |1.0479 & 0.9434 & 0.9886 & \begin{tabular}{|c|}
1.0537 \\
\end{tabular} & \begin{tabular}{|l|}
1.0201 \\
\end{tabular} & 1.0749 & \begin{tabular}{|l|}
0.8994 \\
\end{tabular} & 1.0048 & 0.9037 & \begin{tabular}{|l|}
1.0106 \\
\end{tabular} & 0.9309 & 0.9407 \\
\hline Atl. de Madrid & & & & & & & & & & & & & & & & \begin{tabular}{|l|}
0.8840 \\
\end{tabular} & 1.0391 & 0.9186 & & & \\
\hline Bayern München & 0.9568 & \begin{tabular}{|l|}
1.0161 \\
\end{tabular} & 0.9722 & 0.9960 & 0.9653 & 0.9614 & 0.9594 & 1.0333 & 0.9914 & & & & & & & 1.0449 & \begin{tabular}{|l|}
1.0187 \\
\end{tabular} & 1.0645 & \begin{tabular}{|l|}
0.9639 \\
\end{tabular} & 0.9564 & 0.9218 \\
\hline Benfica & & & & & & & 1.0000 & 1.0181 & 1.0181 & 0.9155 & 0.9698 & 0.8878 & & & & & & & & & \\
\hline Celtic & 0.9735 & 1.0460 & 1.0183 & & & & & & & \begin{tabular}{|l|}
1.0000 \\
\end{tabular} & 1.0000 & 1.0000 & \begin{tabular}{|l|}
1.0000 \\
\end{tabular} & \begin{tabular}{|l|}
1.0000 \\
\end{tabular} & \begin{tabular}{|l|}
1.0000 \\
\end{tabular} & & & & & & \\
\hline Chelsea & 1.0419 & 1.0075 & 1.0497 & 0.9352 & 0.9895 & \begin{tabular}{|l|}
0.9254 \\
\end{tabular} & 1.0680 & 0.9919 & 1.0593 & 0.9870 & 0.9815 & 0.9687 & \begin{tabular}{|l|}
1.0144 \\
\end{tabular} & 1.0100 & 1.0245 & 0.9348 & 1.0266 & 0.9597 & 1.0035 & 0.9288 & 0.9321 \\
\hline CSKA Moscu & & & & & & & & & & 0.9133 & 1.0115 & 0.9238 & & & & & & & & & \\
\hline Dep. A Coruña & 0.9279 & 1.0498 & 0.9741 & & & & & & & & & & & & & & & & & & \\
\hline F.C. Barcelona & & & & 1.1721 & 0.9862 & 1.1558 & 0.9035 & 0.9880 & 0.8926 & 1.1068 & \begin{tabular}{|l|}
0.9763 \\
\end{tabular} & 1.0805 & \begin{tabular}{|l|}
1.0000 \\
\end{tabular} & \begin{tabular}{|l|}
1.0000 \\
\end{tabular} & 1.0000 & \begin{tabular}{|l|}
1.0000 \\
\end{tabular} & 1.0261 & 1.0261 & \begin{tabular}{|l|}
1.0000 \\
\end{tabular} & 0.9569 & 0.9569 \\
\hline FC Dynamo Kyiv & 1.0592 & 1.0298 & 1.0908 & & & & & & & 1.0529 & 0.9841 & 1.0361 & 0.9946 & 1.0389 & 1.0333 & 1.0221 & 1.0148 & 1.0372 & & & \\
\hline FC Porto & 0.8682 & 1.0237 & 0.8887 & 1.0488 & 0.9583 & \begin{tabular}{|l|}
1.0051 \\
\end{tabular} & 0.9988 & 1.0253 & 1.0241 & \begin{tabular}{|l|}
1.0103 \\
\end{tabular} & 0.9186 & 0.9281 & \begin{tabular}{|l|}
1.0883 \\
\end{tabular} & 1.0110 & 1.1002 & 0.9347 & 1.0628 & 0.9934 & & & \\
\hline FC Shakhtar & & & & & & & & & & \begin{tabular}{|l|}
1.0226 \\
\end{tabular} & 0.9438 & 0.9651 & \begin{tabular}{|l|}
0.9703 \\
\end{tabular} & \begin{tabular}{|l|}
1.0341 \\
\end{tabular} & \begin{tabular}{|l|}
1.0034 \\
\end{tabular} & & & & & & \\
\hline Fenerbache & & & & 1.0216 & 0.9613 & \begin{tabular}{|l|}
0.9820 \\
\end{tabular} & & & & & & & \begin{tabular}{|l|}
0.9061 \\
\end{tabular} & \begin{tabular}{|l|}
1.0286 \\
\end{tabular} & \begin{tabular}{|l|}
0.9320 \\
\end{tabular} & & & & & & \\
\hline Fiorentina & & & & & & & & & & & & & & & & 1.0134 & \begin{tabular}{|l|}
1.0274 \\
\end{tabular} & \begin{tabular}{|l|}
1.0412 \\
\end{tabular} & & & \\
\hline Girondins & & & & & & & & & & & & & & & & 1.0539 & \begin{tabular}{|l|}
1.0137 \\
\end{tabular} & \begin{tabular}{|l|}
1.0683 \\
\end{tabular} & & & \\
\hline Inter & 1.0901 & \begin{tabular}{|l|}
1.0336 \\
\end{tabular} & 1.1268 & 0.9350 & \begin{tabular}{|l|}
0.9810 \\
\end{tabular} & \begin{tabular}{|l|}
0.9172 \\
\end{tabular} & 1.0518 & 1.0184 & 1.0712 & 1.0045 & \begin{tabular}{|l|}
0.9946 \\
\end{tabular} & 0.9991 & 0.9415 & \begin{tabular}{|l|}
1.0215 \\
\end{tabular} & \begin{tabular}{|l|}
0.9618 \\
\end{tabular} & \begin{tabular}{|l|}
1.0853 \\
\end{tabular} & \begin{tabular}{|l|}
1.0048 \\
\end{tabular} & \begin{tabular}{|l|}
1.0905 \\
\end{tabular} & \begin{tabular}{|l|}
0.9797 \\
\end{tabular} & 0.9593 & 0.9398 \\
\hline Juventus FC & 0.9842 & \begin{tabular}{|l|}
1.0339 \\
\end{tabular} & 1.0176 & 1.0586 & \begin{tabular}{|l|}
0.9483 \\
\end{tabular} & \begin{tabular}{|l|}
1.0039 \\
\end{tabular} & & & & & & & & & & 0.9865 & \begin{tabular}{|l|}
1.0472 \\
\end{tabular} & 1.0330 & & & \\
\hline Lille & & & & & & & 0.9929 & 1.0393 & 1.0319 & & & & & & & & & & & & \\
\hline Liverpool & & & & 0.9352 & \begin{tabular}{|l|}
0.9991 \\
\end{tabular} & 0.9344 & 1.0693 & 1.0380 & 1.1100 & 1.0000 & 1.0000 & 1.0000 & 0.9758 & \begin{tabular}{|l|}
1.0136 \\
\end{tabular} & \begin{tabular}{|l|}
0.9891 \\
\end{tabular} & \begin{tabular}{|l|}
0.9678 \\
\end{tabular} & 1.0086 & \begin{tabular}{|l|}
0.9762 \\
\end{tabular} & & & \\
\hline Lyon & 0.9429 & 1.0261 & 0.9675 & 1.0664 & 0.9545 & 1.0179 & 0.8782 & 1.0664 & 0.9366 & \begin{tabular}{|l|}
1.1473 \\
\end{tabular} & 0.9344 & 1.0721 & \begin{tabular}{|l|}
1.0242 \\
\end{tabular} & \begin{tabular}{|l|}
1.0108 \\
\end{tabular} & \begin{tabular}{|l|}
1.0353 \\
\end{tabular} & 1.0007 & \begin{tabular}{|l|}
1.0308 \\
\end{tabular} & \begin{tabular}{|l|}
1.0316 \\
\end{tabular} & \begin{tabular}{|l|}
0.8811 \\
\end{tabular} & 0.9537 & 0.8403 \\
\hline Manchester U & 0.9185 & 1.0257 & 0.9421 & 0.9619 & \begin{tabular}{|l|}
0.9565 \\
\end{tabular} & \begin{tabular}{|l|}
0.9200 \\
\end{tabular} & 1.1319 & 0.9867 & 1.1169 & \begin{tabular}{|l|}
0.9867 \\
\end{tabular} & 0.9832 & 0.9702 & \begin{tabular}{|l|}
1.0001 \\
\end{tabular} & \begin{tabular}{|l|}
1.0169 \\
\end{tabular} & \begin{tabular}{|l|}
1.0170 \\
\end{tabular} & \begin{tabular}{|l|}
1.0060 \\
\end{tabular} & \begin{tabular}{|l|}
1.0277 \\
\end{tabular} & 1.0338 & \begin{tabular}{|l|}
1.0074 \\
\end{tabular} & 0.9640 & 0.9711 \\
\hline Milan AC & 1.0989 & 1.0038 & 1.1031 & 1.0000 & \begin{tabular}{|l|}
0.9687 \\
\end{tabular} & \begin{tabular}{|l|}
0.9687 \\
\end{tabular} & 1.0000 & 1.0000 & 1.0000 & \begin{tabular}{|l|}
0.9241 \\
\end{tabular} & 0.9716 & 0.8978 & & & & & & & \begin{tabular}{|l|}
1.0883 \\
\end{tabular} & 0.9248 & 1.0065 \\
\hline Monaco & 0.9744 & 1.0131 & 0.9871 & & & & & & & & & & & & & & & & & & \\
\hline
\end{tabular}




\begin{tabular}{|c|c|c|c|c|c|c|c|c|c|c|c|c|c|c|c|c|c|c|c|c|c|}
\hline O. Marseille & & & & & & & & & & & & & 0.9710 & 1.0228 & 0.9931 & 1.0357 & 1.0263 & 1.0629 & 1.0027 & 0.9237 & 0.9262 \\
\hline Olympiakos $\mathrm{P}$ & 1.0058 & 1.0629 & 1.0691 & 0.9873 & 0.9558 & 0.9436 & 0.9773 & 1.0149 & 0.9919 & 1.1153 & 0.9773 & 1.0900 & & & & & & & & & \\
\hline Panathinaikos & 0.8924 & 1.0652 & 0.9506 & 1.0689 & 0.9470 & 1.0123 & & & & & & & & & & & & & & & \\
\hline $\begin{array}{l}\text { PSV } \\
\text { Eindhoven }\end{array}$ & 1.0637 & 1.0063 & 1.0704 & 1.0000 & 1.0000 & 1.0000 & 0.9853 & 0.9826 & 0.9682 & 0.9608 & 0.9885 & 0.9497 & 0.9586 & 1.0346 & 0.9917 & & & & & & \\
\hline Rangers FC & & & & & & & & & & & & & & & & & & & 1.0064 & 0.9919 & 0.9983 \\
\hline Real Madrid & 0.9682 & 1.0183 & 0.9858 & 1.0020 & 0.9459 & 0.9478 & 0.9490 & 1.0079 & 0.9565 & 1.0102 & 0.9373 & 0.9468 & 0.9738 & 1.0194 & 0.9926 & 1.0125 & 1.0118 & 1.0244 & 1.1729 & 0.9026 & 1.0587 \\
\hline Rosenborg & & & & 1.0739 & 0.9725 & 1.0443 & & & & & & & & & & & & & & & \\
\hline $\begin{array}{l}\text { RSC } \\
\text { Anderlecht }\end{array}$ & 0.8268 & 1.0385 & 0.8586 & 1.2095 & 0.9312 & 1.1263 & 0.9152 & 1.0166 & 0.9304 & & & & & & & & & & & & \\
\hline Rubin Kazan & & & & & & & & & & & & & & & & & & & 0.9687 & 0.9863 & 0.9555 \\
\hline Sparta Praha & 0.9223 & 1.0653 & 0.9825 & 1.0665 & 0.9737 & 1.0384 & & & & & & & & & & & & & & & \\
\hline $\begin{array}{l}\text { Sporting de } \\
\text { Lisboa }\end{array}$ & & & & & & & & & & & & & 1.0504 & 1.0309 & 1.0829 & & & & & & \\
\hline $\begin{array}{l}\text { Steaua } \\
\text { Bucarest }\end{array}$ & & & & & & & & & & 0.9115 & 1.0255 & 0.9348 & 1.0387 & 1.0096 & 1.0487 & & & & & & \\
\hline Valencia & & & & & & & & & & 0.9665 & 1.0051 & 0.9714 & & & & & & & & & \\
\hline $\begin{array}{l}\text { Werder } \\
\text { Bremen }\end{array}$ & & & & 1.0767 & 0.9794 & 1.0545 & 0.9245 & 1.0667 & 0.9862 & 0.9589 & 0.9684 & 0.9286 & 0.9690 & 1.0276 & 0.9957 & & & & & & \\
\hline Average & 0.98 & 1.03 & 1.01 & 1.0325 & 0.9673 & 0.9983 & 0.98 & 1.02 & 1.00 & 1.01 & 0.97 & 0.98 & 1.00 & 1.02 & 1.02 & 0.99 & 1.02 & 1.02 & 1.01 & 0.95 & 0.95 \\
\hline
\end{tabular}

Note: 1: Efficiency change, 2. Technical change, 3: Malmquist.

Source: Authors' estimations. 
The other three that showed technical progress (CSKA Moscu, Steaua Bucarest and Valencia) could not, however, offset their decrease in efficiency, therefore their productivity dropped. Of those showing technical regression and increased efficiency, four of them increased their productivity (FC Barcelona, FC Dynamo Kyiv, Lyon and Olympiakos P), while the productivity decreased for six (AC Roma, Arsenal, FC Porto, FC Shakhtar, Inter and Real Madrid).

In summary, in view of the results, it could be said that on average, for the seasons that show increases in productivity, those increases are due to technical progress. When the performance of the teams is analyzed individually, the evolution of efficiency only appears to have a greater influence on the change in productivity during the seasons 2005/2006 and 2006/2007, since in the majority of the cases in which the change in efficiency shows the opposite sign of that for technical progress, efficiency prevails. In the rest of the seasons, with the exception of 2007/2008 for which the influence is inconclusive, it is the technical progress or regression that dominates the sign of the change in productivity when it does not coincide with the sign of the change in efficiency.

If the results are analyzed team by team, it should be noted that the teams that play the UEFA Champions League in all of the seasons analyzed in this study show erratic changes in productivity, alternating increases with decreases and showing a drop at the end of the period. The only exception is Real Madrid, which has a Malmquist index below unity for every season analyzed except for the last two, when its productivity increases. Among the teams that do not play the UEFA Champions League in all of the seasons analyzed, but for which there are values of their changes in productivity for at least two of the seasons, it can be seen that AC Roma, FC Dynamo Kyiv and Juventus FC always increase their productivity, Celtic increases or maintains it and it decreases for Fenerbache in all of the cases. The evolution of the productivity of the rest does not follow any defined pattern. Finally, among the teams for which a Malmquist index value could only be calculated once during the span of this study, the productivity of some teams decreased, while for others it increased.

The change in productivity and its two components were also calculated for the teams that participated in the UEFA Champions League in the seasons $2003 / 2004$ and 2010/2011, as if they had been consecutive years, with the objective of approximating the evolution of their productivity over the entire period analyzed in this paper. The results are shown in Table 3.

On average the results show a decrease in productivity, a decrease in efficiency and technical regression. If the results are interpreted individually for each team, only AC Milan increases its productivity, due to an increase in efficiency that compensates for its technical regression. On the other hand, Panathinaikos and Rangers FC experience no change in productivity or efficiency and show neither technical progress nor regression. 
Table 3. Malmquist Index Values for the Teams Participating in the UEFA Champions League in the First and Last Seasons of the Period Analyzed

\begin{tabular}{|l|c|c|c|}
\hline \multicolumn{1}{|c|}{$\mathbf{2 0 1 0 / 2 0 1 1}$ over 2003/2004 } & Efficiency change & Technical change & Malmquist \\
\hline Ajax & 0.9951 & 0.9492 & 0.9446 \\
\hline Arsenal & 0.9589 & 0.9857 & 0.9451 \\
\hline Bayern Munchen & 0.9759 & 0.9294 & 0.9070 \\
\hline Chelsea & 0.9774 & 0.9696 & 0.9477 \\
\hline FK Partizan & 0.8972 & 1.0340 & 0.9277 \\
\hline Inter & 1.0781 & 0.9098 & 0.9809 \\
\hline Lyon & 0.9150 & 0.9694 & 0.8869 \\
\hline Manchester United & 1.0000 & 0.9818 & 0.9818 \\
\hline Milan AC & 1.0833 & 0.9497 & 1.0288 \\
\hline Panathinaikos & 1.0000 & 1.0000 & 1.0000 \\
\hline Rangers FC & 1.0000 & 1.0000 & 1.0000 \\
\hline Real Madrid & 1.0754 & 0.9241 & 0.9937 \\
\hline Average & $\mathbf{0 . 9 9 6 4}$ & $\mathbf{0 . 9 6 6 9}$ & $\mathbf{0 . 9 6 2 0}$ \\
\hline
\end{tabular}

Source: Authors' estimations.

The rest of the teams show a decline in productivity, most of them due to a drop in both efficiency and technical progress, however, both Inter and Real Madrid increase their efficiency, for Manchester United remains unchanged, and FK Partizan shows technical progress. Analyzing the information in Table 3 , one could conclude that over the period studied there is a widespread decline in productivity, which is also evident in its two components, but primarily in a technical regression.

\section{Conclusions}

The product of the football teams is the entertainment they offer, while their productive activity is the games played; the resources consumed are the plays made during the games. Since it is a process that could be considered labor intensive, studies such as the present, which evaluate the utilization of the resources consumed, can be interpreted from the point of view close to that of the coach who is in charge of designing the tactics implemented on the field and the utilization of the resources available. However, the fundamentals of the study are underpinned by tools supplied by the economic science and especially, adopting an organizational management perspective. With regards to this it should be stressed that the plays executed by each individual player during the game and their contribution to the final result, could be considered an application to football teams of the ideas set forth by the administration theory. Recently, there have been reports in the sports press about football coaches making use of very detailed statistics of the plays made on the field ${ }^{13}$. The use of this information can serve to improve the performance of the players, both in training and during the games. This type of information and the purpose, for which it is used, could be linked to the pioneering studies of the classical approach to management, which focused on work methods, the

\footnotetext{
${ }^{13}$ An example would be found in the web page: http://goo.gl/7y3WX5.
} 
movements necessary to execute a task and the time required for its execution (Chiavenato 1999).

Teams that participate in a football championship compete among themselves for the sports result, but are not considered competitors in the market from which they obtain the revenues that are a component of their economic profit. Consequently, the index of productivity can be related to the economic competitiveness of the organizations within their economic sector.

In this article, changes in productivity in football teams playing in UEFA Champions League from 2003-2011 have been calculated by means of the Malmquist index. Also, efficiency ratios needed to calculate the Malmquist index have been obtained using DEA. As a non-parametric and deterministic tool, DEA does not need the specification of a functional form for a productive process. But this lack of constraints makes results sensitive to the sample analyzed. In the present article this difficulty have be overcome: the sample under analysis is well defined, as every single team participating in the UEFA Champions League during time horizon has been included in the sample, even if its participation has been reduced to a unique season and it has not been possible to calculate its Malmquist index. Of course, the choice of variables representing inputs and outputs have a big influence in numerical results. In order to present more robust indexes, we have focused on games as the productive area in football teams and only variables measured in physical units have been considered here.

The results obtained in this article show no clear increase in productivity during the period studied, both on the average and individually. In conclusion, it does not appear that the organizer of this tournament has been able to increase the productivity of the teams that has participated in it during the period analyzed.

In this respect it could be said that the UEFA Champions League is an entertainment alternative whose competitiveness relative to other options could be threatened. If the football teams that participate in the tournament showed a consistent and prolonged increase in productivity, they would be able to afford an increase in the cost of their factors of production in the same proportion without having to transfer these increases to the prices. Consequently, the overall recommendation for the football clubs analyzed in this study would be to improve their productivity. Breaking down the Malmquist index into efficiency change and technical change and seeing that neither of the two show a clear increase, the general recommendation can be made more specific: if the UEFA Champions League pretends to stay competitive with other competitors in the entertainment sector (that means, to afford increases in the retribution of its factors of production without increasing the price at which it offers its entertainment or to make the participating teams more profitable), first the teams should eliminate all use of factors of production that could be considered excessive and choose a combination of them that is on the isoquant and second they should introduce improvements in the use of their resources that would suppose technical progress, in other words that would make the isoquant approach the origin of the coordinate system. 
Therefore, the recommendation would be to design rules for the tournament that would improve the productivity of the participating teams by linking sports success to the increase in productivity. The lack of a relationship between the sports results and the evolution of the productivity of the teams that participate in the UEFA Champions League is also revealed by the fact that obtaining a Malmquist index above one does not guarantee their continuity in the competition since for AC Roma, Celtic, FC Dynamo Kyiv, FC Shakhtar, Juventus FC, Olympiakos P, Panathinaikos, Sparta Praha and Steaua Bucarest their series end in seasons in which they increased their productivity and the cases in which only one Malmquist index could be calculated during the period studied corroborate these findings, since increased productivity did not guarantee permanence in the competition. Therefore, the value of the Malmquist index for the teams that participate in the tournament is not related to their permanency in the competition.

Future lines of research could involve relating the productivity values to the evolution of the economic profits or other variables that are representative of the team's economic survival and the search for rules that reward and value the sports results achieved as a result of increases in productivity.

\section{Acknowledgements}

We would like to thank GECA Sport for its cooperation in providing the data for this study. This work was done within compete research group and was funded by project ECO2012-36290-C03-01 from Micinn and Feder.

\section{Appendix}

Table A1. Descriptive Statistics of the Variables Used for Teams in the Sample

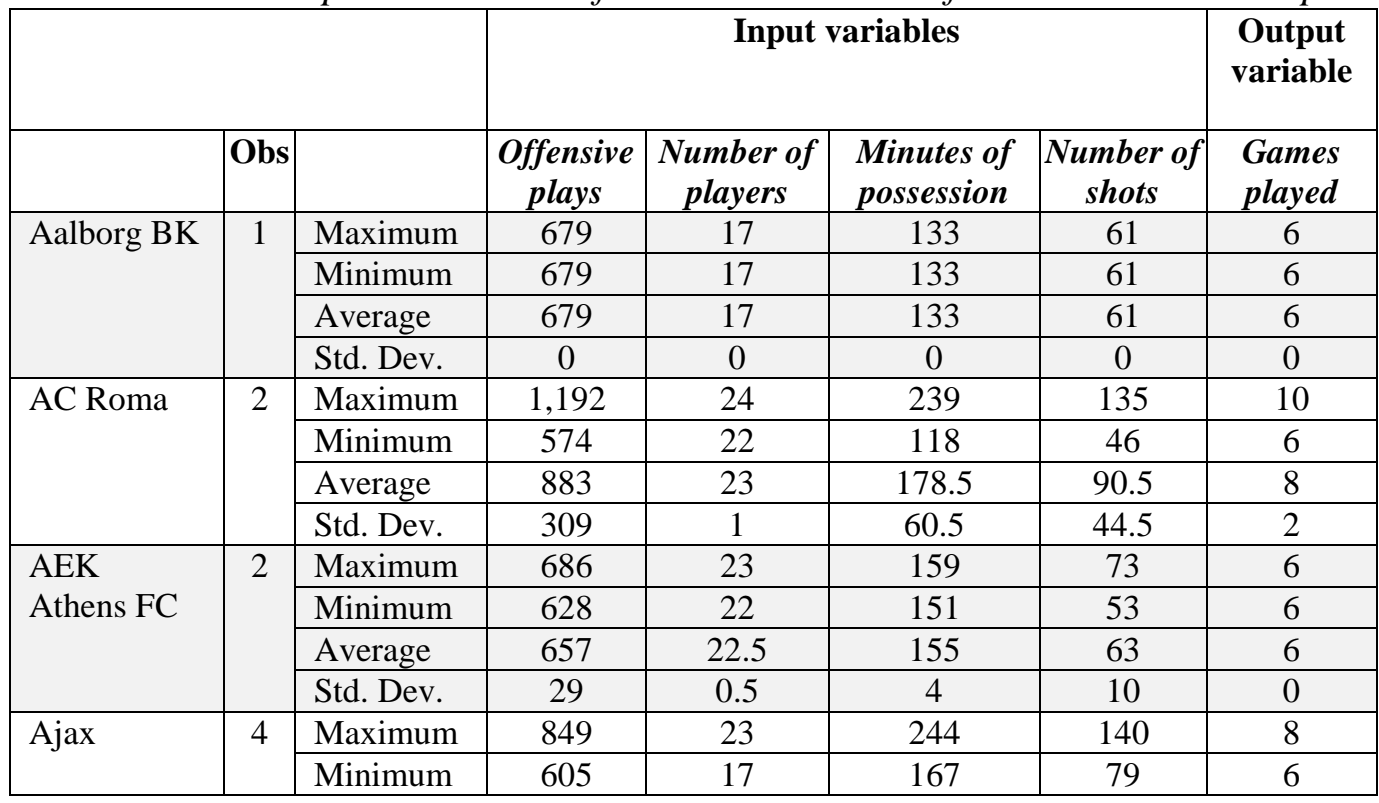




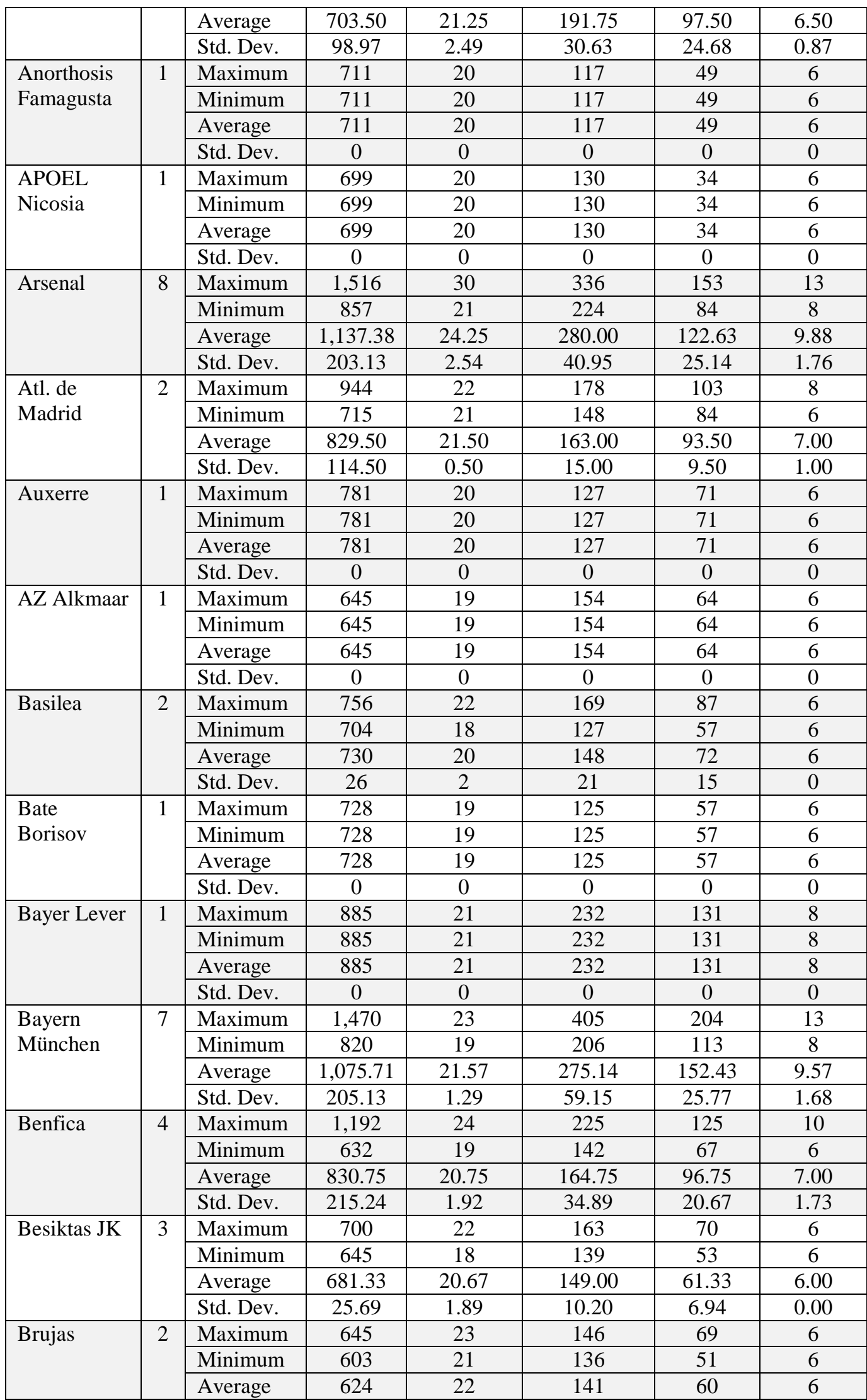




\begin{tabular}{|c|c|c|c|c|c|c|c|}
\hline & & Std. Dev. & 21 & 1 & 5 & 9 & 0 \\
\hline \multirow[t]{4}{*}{ Bursaspor } & \multirow[t]{4}{*}{1} & Maximum & 710 & 21 & 144 & 64 & 6 \\
\hline & & Minimum & 710 & 21 & 144 & 64 & 6 \\
\hline & & Average & 710 & 21 & 144 & 64 & 6 \\
\hline & & Std. Dev. & 0 & 0 & 0 & 0 & 0 \\
\hline \multirow[t]{4}{*}{ Celtic } & \multirow[t]{4}{*}{5} & Maximum & 934 & 23 & 211 & 73 & 8 \\
\hline & & Minimum & 608 & 19 & 134 & 61 & 6 \\
\hline & & Average & 732.00 & 20.40 & 164.60 & 66.60 & 6.80 \\
\hline & & Std. Dev. & 139.45 & 1.50 & 28.86 & 4.27 & 0.98 \\
\hline \multirow{4}{*}{$\begin{array}{l}\text { CFR } 1907 \\
\text { Cluj Napoca }\end{array}$} & \multirow[t]{4}{*}{2} & Maximum & 718 & 22 & 134 & 73 & 6 \\
\hline & & Minimum & 703 & 18 & 120 & 67 & 6 \\
\hline & & Average & 710.50 & 20.00 & 127.00 & 70.00 & 6.00 \\
\hline & & Std. Dev. & 7.50 & 2.00 & 7.00 & 3.00 & 0.00 \\
\hline \multirow[t]{4}{*}{ Chelsea } & \multirow[t]{4}{*}{8} & Maximum & 1,559 & 25 & 364 & 216 & 13 \\
\hline & & Minimum & 903 & 21 & 203 & 91 & 8 \\
\hline & & Average & $1,260.63$ & 23.00 & 288.50 & 161.63 & 10.88 \\
\hline & & Std. Dev. & 221.98 & 1.32 & 54.72 & 37.79 & 1.83 \\
\hline \multirow[t]{4}{*}{ Copenhague } & \multirow[t]{4}{*}{1} & Maximum & 948 & 19 & 190 & 80 & 8 \\
\hline & & Minimum & 948 & 19 & 190 & 80 & 8 \\
\hline & & Average & 948 & 19 & 190 & 80 & 8 \\
\hline & & Std. Dev. & 0 & 0 & 0 & 0 & 0 \\
\hline \multirow{4}{*}{$\begin{array}{l}\text { CSKA } \\
\text { Moscu }\end{array}$} & \multirow[t]{4}{*}{4} & Maximum & 1,147 & 22 & 243 & 119 & 10 \\
\hline & & Minimum & 682 & 19 & 139 & 50 & 6 \\
\hline & & Average & 832.25 & 20.25 & 172.75 & 81.00 & 7.00 \\
\hline & & Std. Dev. & 184.13 & 1.09 & 41.72 & 24.67 & 1.73 \\
\hline \multirow[t]{4}{*}{ Debreceni } & \multirow[t]{4}{*}{1} & Maximum & 632 & 20 & 121 & 63 & 6 \\
\hline & & Minimum & 632 & 20 & 121 & 63 & 6 \\
\hline & & Average & 632 & 20 & 121 & 63 & 6 \\
\hline & & Std. Dev. & 0 & 0 & 0 & 0 & 0 \\
\hline \multirow{4}{*}{$\begin{array}{l}\text { Dep. A } \\
\text { Coruña }\end{array}$} & \multirow[t]{4}{*}{2} & Maximum & 1,433 & 22 & 327 & 149 & 12 \\
\hline & & Minimum & 718 & 21 & 165 & 56 & 6 \\
\hline & & Average & $1,075.50$ & 21.50 & 246.00 & 102.50 & 9.00 \\
\hline & & Std. Dev. & 357.50 & 0.50 & 81.00 & 46.50 & 3.00 \\
\hline \multirow{4}{*}{$\begin{array}{l}\text { FC } \\
\text { Barcelona }\end{array}$} & \multirow[t]{4}{*}{7} & Maximum & 1,630 & 26 & 501 & 220 & 13 \\
\hline & & Minimum & 936 & 20 & 234 & 99 & 8 \\
\hline & & Average & $1,318.43$ & 22.57 & 385.71 & 185.86 & 11.29 \\
\hline & & Std. Dev. & 257.61 & 1.76 & 83.48 & 41.05 & 2.12 \\
\hline \multirow{4}{*}{$\begin{array}{l}\text { FC Dynamo } \\
\text { Kyiv }\end{array}$} & 6 & Maximum & 748 & 27 & 152 & 91 & 6 \\
\hline & & Minimum & 580 & 17 & 117 & 67 & 6 \\
\hline & & Average & 665.17 & 21.17 & 136.33 & 79.67 & 6.00 \\
\hline & & Std. Dev. & 48.63 & 3.85 & 12.27 & 9.34 & 0.00 \\
\hline & 1 & Maximum & 690 & 18 & 140 & 55 & 6 \\
\hline Artmedia & & Minimum & 690 & 18 & 140 & 55 & 6 \\
\hline & & Average & 690 & 18 & 140 & 55 & 6 \\
\hline & & Std. Dev. & 0 & 0 & 0 & 0 & 0 \\
\hline FC Københ & 1 & Maximum & 686 & 17 & 128 & 63 & 6 \\
\hline & & Minimum & 686 & 17 & 128 & 63 & 6 \\
\hline & & Average & 686 & 17 & 128 & 63 & 6 \\
\hline & & Std. Dev. & 0 & 0 & 0 & 0 & 0 \\
\hline FC Porto & 4 & Maximum & 1,378 & 24 & 355 & 180 & 13 \\
\hline & & Minimum & 668 & 22 & 160 & 98 & 6 \\
\hline & & Average & 969.50 & 22.75 & 234.25 & 133.50 & 8.75 \\
\hline & & Std. Dev. & 256.69 & 0.83 & 74.26 & 33.03 & 2.59 \\
\hline
\end{tabular}




\begin{tabular}{|c|c|c|c|c|c|c|c|}
\hline \multirow{4}{*}{$\begin{array}{l}\text { FC } \\
\text { Schalke04 }\end{array}$} & \multirow[t]{4}{*}{1} & Maximum & 612 & 16 & 162 & 95 & 6 \\
\hline & & Minimum & 612 & 16 & 162 & 95 & 6 \\
\hline & & Average & 612 & 16 & 162 & 95 & 6 \\
\hline & & Std. Dev. & 0 & 0 & 0 & 0 & 0 \\
\hline \multirow{4}{*}{ FC Shakhtar } & \multirow[t]{4}{*}{5} & Maximum & 1,208 & 22 & 254 & 106 & 10 \\
\hline & & Minimum & 576 & 17 & 148 & 68 & 6 \\
\hline & & Average & 753.40 & 20.60 & 173.60 & 87.80 & 6.80 \\
\hline & & Std. Dev. & 229.82 & 1.96 & 40.47 & 16.40 & 1.60 \\
\hline \multirow[t]{4}{*}{ FC Thun } & \multirow[t]{4}{*}{1} & Maximum & 674 & 19 & 131 & 68 & 6 \\
\hline & & Minimum & 674 & 19 & 131 & 68 & 6 \\
\hline & & Average & 674 & 19 & 131 & 68 & 6 \\
\hline & & Std. Dev. & 0 & 0 & 0 & 0 & 0 \\
\hline \multirow[t]{4}{*}{ Fenerbache } & \multirow[t]{4}{*}{4} & Maximum & 1,190 & 21 & 256 & 155 & 10 \\
\hline & & Minimum & 611 & 17 & 161 & 63 & 6 \\
\hline & & Average & 782.25 & 19.25 & 185.75 & 91.75 & 7.00 \\
\hline & & Std. Dev. & 237.70 & 1.48 & 40.57 & 36.82 & 1.73 \\
\hline \multirow[t]{4}{*}{ Fiorentina } & \multirow[t]{4}{*}{2} & Maximum & 895 & 24 & 186 & 103 & 8 \\
\hline & & Minimum & 752 & 20 & 131 & 93 & 6 \\
\hline & & Average & 823.50 & 22.00 & 158.50 & 98.00 & 7.00 \\
\hline & & Std. Dev. & 71.50 & 2.00 & 27.50 & 5.00 & 1.00 \\
\hline \multirow[t]{4}{*}{ FK Partizan } & \multirow[t]{4}{*}{2} & Maximum & 801 & 22 & 159 & 72 & 6 \\
\hline & & Minimum & 638 & 21 & 147 & 61 & 6 \\
\hline & & Average & 719.50 & 21.50 & 153.00 & 66.50 & 6.00 \\
\hline & & Std. Dev. & 81.50 & 0.50 & 6.00 & 5.50 & 0.00 \\
\hline \multirow[t]{4}{*}{ G. Rangers } & \multirow[t]{4}{*}{3} & Maximum & 705 & 19 & 134 & 60 & 6 \\
\hline & & Minimum & 624 & 18 & 121 & 48 & 6 \\
\hline & & Average & 668.00 & 18.67 & 129.33 & 53.67 & 6.00 \\
\hline & & Std. Dev. & 33.44 & 0.47 & 5.91 & 4.92 & 0.00 \\
\hline \multirow[t]{4}{*}{ Galatasaray } & \multirow[t]{4}{*}{2} & Maximum & 699 & 24 & 174 & 66 & 6 \\
\hline & & Minimum & 654 & 22 & 149 & 60 & 6 \\
\hline & & Average & 676.50 & 23.00 & 161.50 & 63.00 & 6.00 \\
\hline & & Std. Dev. & 22.50 & 1.00 & 12.50 & 3.00 & 0.00 \\
\hline \multirow[t]{4}{*}{ Girondins } & \multirow[t]{4}{*}{3} & Maximum & 1,118 & 23 & 254 & 132 & 10 \\
\hline & & Minimum & 684 & 19 & 148 & 73 & 6 \\
\hline & & Average & 844.33 & 21.00 & 189.00 & 95.00 & 7.33 \\
\hline & & Std. Dev. & 194.46 & 1.63 & 46.48 & 26.32 & 1.89 \\
\hline \multirow[t]{4}{*}{ Hamburger } & 1 & Maximum & 710 & 24 & 149 & 100 & 6 \\
\hline & & Minimum & 710 & 24 & 149 & 100 & 6 \\
\hline & & Average & 710 & 24 & 149 & 100 & 6 \\
\hline & & Std. Dev. & 0 & 0 & 0 & 0 & 0 \\
\hline Hapoel Tel & 1 & Maximum & 702 & 19 & 155 & 55 & 6 \\
\hline Aviv & & Minimum & 702 & 19 & 155 & 55 & 6 \\
\hline & & Average & 702 & 19 & 155 & 55 & 6 \\
\hline & & Std. Dev. & 0 & 0 & 0 & 0 & 0 \\
\hline Inter & 8 & Maximum & 1,457 & 29 & 289 & 168 & 13 \\
\hline & & Minimum & 667 & 22 & 162 & 84 & 6 \\
\hline & & Average & $1,024.88$ & 24.63 & 227.88 & 123.50 & 9.13 \\
\hline & & Std. Dev. & 220.60 & 2.29 & 41.76 & 30.52 & 1.96 \\
\hline Juventus FC & 5 & Maximum & 1,195 & 25 & 273 & 148 & 10 \\
\hline & & Minimum & 659 & 21 & 128 & 70 & 6 \\
\hline & & Average & 984.80 & 22.80 & 212.20 & 111.80 & 8.40 \\
\hline & & Std. Dev. & 198.76 & 1.47 & 56.20 & 26.19 & 1.50 \\
\hline Lazio & 1 & Maximum & 715 & 21 & 135 & 67 & 6 \\
\hline
\end{tabular}




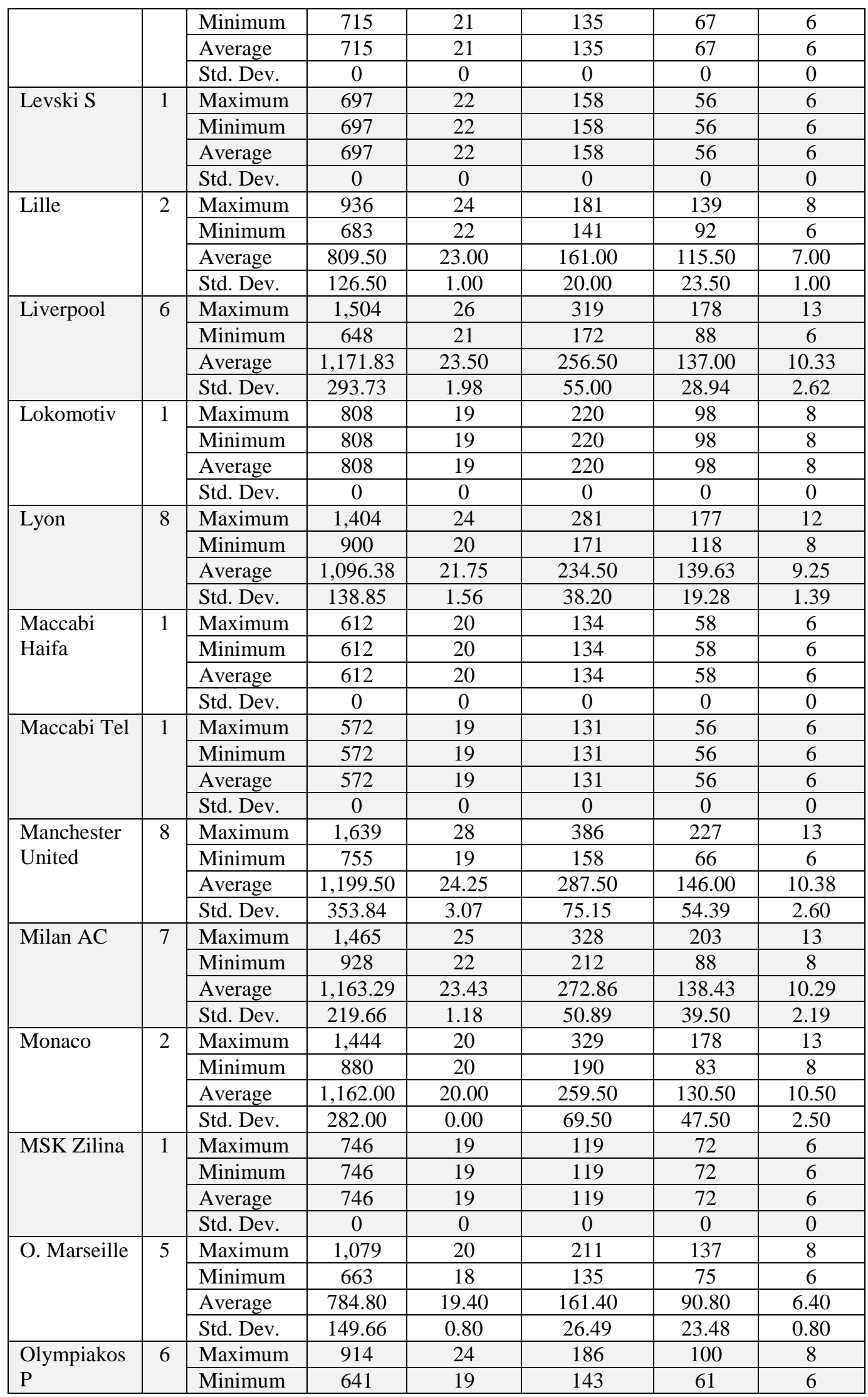




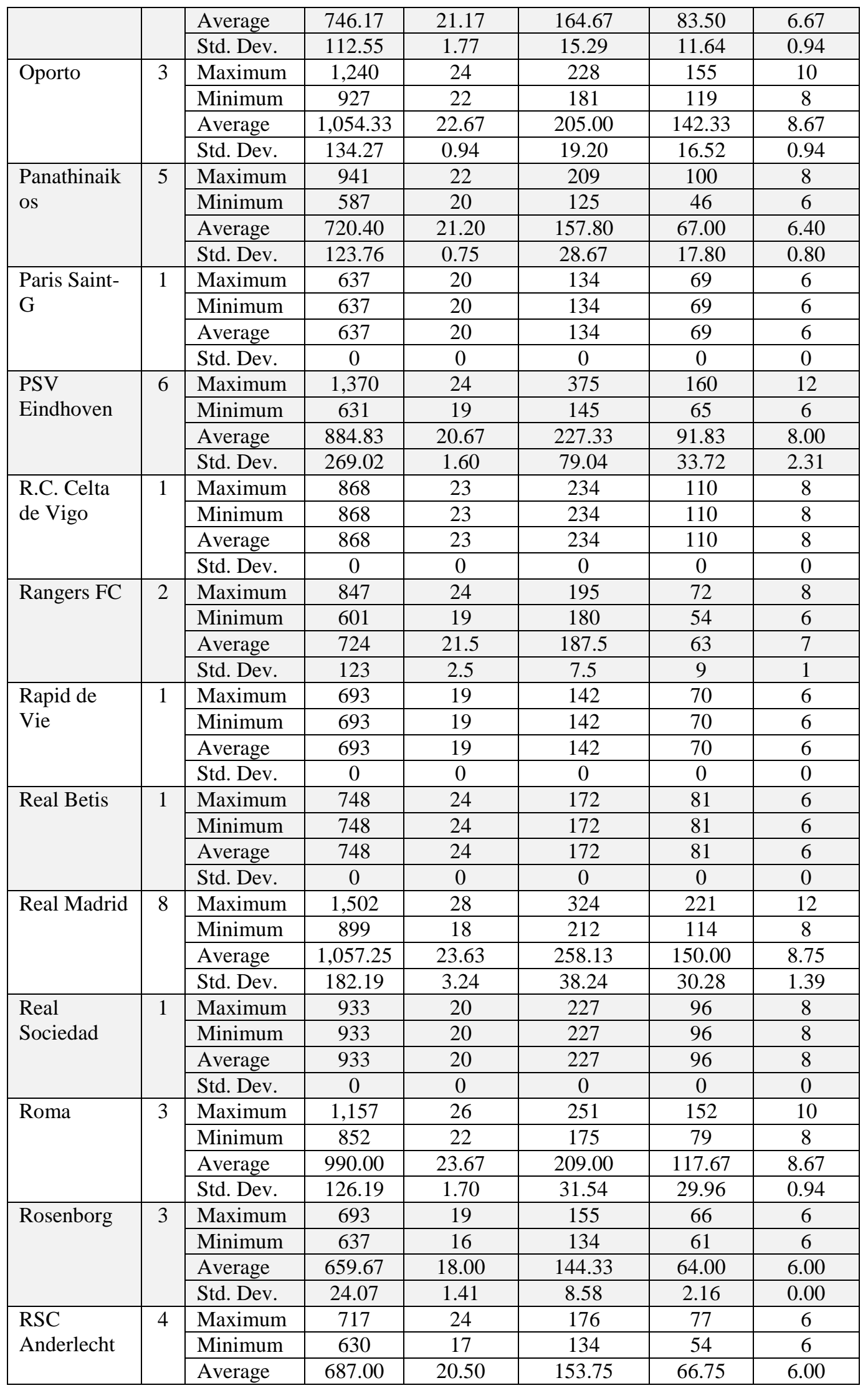




\begin{tabular}{|c|c|c|c|c|c|c|c|}
\hline & & Std. Dev. & 33.64 & 2.69 & 17.33 & 10.40 & 0.00 \\
\hline \multirow{4}{*}{$\begin{array}{l}\text { Rubin } \\
\text { Kazan }\end{array}$} & \multirow[t]{4}{*}{2} & Maximum & 726 & 20 & 125 & 61 & 6 \\
\hline & & Minimum & 662 & 17 & 122 & 47 & 6 \\
\hline & & Average & 694.00 & 18.50 & 123.50 & 54.00 & 6.00 \\
\hline & & Std. Dev. & 32.00 & 1.50 & 1.50 & 7.00 & 0.00 \\
\hline \multirow[t]{4}{*}{ Schalke 04} & \multirow[t]{4}{*}{2} & Maximum & 1,501 & 27 & 270 & 156 & 12 \\
\hline & & Minimum & 1,256 & 23 & 237 & 141 & 10 \\
\hline & & Average & $1,378.50$ & 25.00 & 253.50 & 148.50 & 11.00 \\
\hline & & Std. Dev. & 122.50 & 2.00 & 16.50 & 7.50 & 1.00 \\
\hline \multirow[t]{4}{*}{ Sevilla F.C. } & \multirow[t]{4}{*}{2} & Maximum & 1,025 & 25 & 235 & 142 & 8 \\
\hline & & Minimum & 893 & 25 & 208 & 107 & 8 \\
\hline & & Average & 959.00 & 25.00 & 221.50 & 124.50 & 8.00 \\
\hline & & Std. Dev. & 66.00 & 0.00 & 13.50 & 17.50 & 0.00 \\
\hline \multirow{4}{*}{$\begin{array}{l}\text { Slavia de } \\
\text { Praga }\end{array}$} & \multirow[t]{4}{*}{1} & Maximum & 684 & 23 & 126 & 44 & 6 \\
\hline & & Minimum & 684 & 23 & 126 & 44 & 6 \\
\hline & & Average & 684 & 23 & 126 & 44 & 6 \\
\hline & & Std. Dev. & 0 & 0 & 0 & 0 & 0 \\
\hline \multirow[t]{4}{*}{ Sparta Praha } & \multirow[t]{4}{*}{3} & Maximum & 830 & 25 & 188 & 91 & 8 \\
\hline & & Minimum & 665 & 19 & 134 & 72 & 6 \\
\hline & & Average & 726.00 & 21.00 & 155.00 & 82.33 & 6.67 \\
\hline & & Std. Dev. & 73.91 & 2.83 & 23.62 & 7.85 & 0.94 \\
\hline \multirow{4}{*}{$\begin{array}{l}\text { Spartak } \\
\text { Moscú }\end{array}$} & \multirow[t]{4}{*}{2} & Maximum & 751 & 23 & 162 & 79 & 6 \\
\hline & & Minimum & 682 & 21 & 159 & 77 & 6 \\
\hline & & Average & 716.50 & 22.00 & 160.50 & 78.00 & 6.00 \\
\hline & & Std. Dev. & 34.50 & 1.00 & 1.50 & 1.00 & 0.00 \\
\hline \multirow{4}{*}{$\begin{array}{l}\text { Sporting } \\
\text { Braga }\end{array}$} & \multirow[t]{4}{*}{1} & Maximum & 786 & 21 & 124 & 66 & 6 \\
\hline & & Minimum & 786 & 21 & 124 & 66 & 6 \\
\hline & & Average & 786 & 21 & 124 & 66 & 6 \\
\hline & & Std. Dev. & 0 & 0 & 0 & 0 & 0 \\
\hline \multirow{4}{*}{$\begin{array}{l}\text { Sporting de } \\
\text { Lisboa }\end{array}$} & \multirow[t]{4}{*}{3} & Maximum & 934 & 23 & 174 & 92 & 8 \\
\hline & & Minimum & 683 & 21 & 150 & 89 & 6 \\
\hline & & Average & 784.67 & 21.67 & 161.33 & 90.33 & 6.67 \\
\hline & & Std. Dev. & 107.87 & 0.94 & 9.84 & 1.25 & 0.94 \\
\hline \multirow[t]{4}{*}{ SS Lazio } & \multirow[t]{4}{*}{1} & Maximum & 669 & 21 & 169 & 85 & 6 \\
\hline & & Minimum & 669 & 21 & 169 & 85 & 6 \\
\hline & & Average & 669 & 21 & 169 & 85 & 6 \\
\hline & & Std. Dev. & 0 & 0 & 0 & 0 & 0 \\
\hline \multirow{4}{*}{$\begin{array}{l}\text { Standard de } \\
\text { Lieja }\end{array}$} & 1 & Maximum & 644 & 19 & 116 & 62 & 6 \\
\hline & & Minimum & 644 & 19 & 116 & 62 & 6 \\
\hline & & Average & 644 & 19 & 116 & 62 & 6 \\
\hline & & Std. Dev. & 0 & 0 & 0 & 0 & 0 \\
\hline Steaua & 3 & Maximum & 721 & 21 & 152 & 63 & 6 \\
\hline Bucarest & & Minimum & 701 & 20 & 128 & 56 & 6 \\
\hline & & Average & 712.00 & 20.33 & 138.00 & 60.33 & 6.00 \\
\hline & & Std. Dev. & 8.29 & 0.47 & 10.20 & 3.09 & 0.00 \\
\hline Stuttgart & 2 & Maximum & 873 & 22 & 206 & 122 & 8 \\
\hline & & Minimum & 658 & 21 & 163 & 88 & 6 \\
\hline & & Average & 765.50 & 21.50 & 184.50 & 105.00 & 7.00 \\
\hline & & Std. Dev. & 107.50 & 0.50 & 21.50 & 17.00 & 1.00 \\
\hline Tottenham & 1 & Maximum & 1,234 & 25 & 243 & 108 & 10 \\
\hline Hotspur & & Minimum & 1,234 & 25 & 243 & 108 & 10 \\
\hline & & Average & 1,234 & 25 & 243 & 108 & 10 \\
\hline & & Std. Dev. & 0 & 0 & 0 & 0 & 0 \\
\hline
\end{tabular}




\begin{tabular}{|c|c|c|c|c|c|c|c|}
\hline \multirow[t]{4}{*}{ Twente } & \multirow[t]{4}{*}{1} & Maximum & 719 & 21 & 146 & 93 & 6 \\
\hline & & Minimum & 719 & 21 & 146 & 93 & 6 \\
\hline & & Average & 719 & 21 & 146 & 93 & 6 \\
\hline & & Std. Dev. & 0 & 0 & 0 & 0 & 0 \\
\hline \multirow[t]{4}{*}{ Udinese } & \multirow[t]{4}{*}{1} & Maximum & 671 & 20 & 132 & 63 & 6 \\
\hline & & Minimum & 671 & 20 & 132 & 63 & 6 \\
\hline & & Average & 671 & 20 & 132 & 63 & 6 \\
\hline & & Std. Dev. & 0 & 0 & 0 & 0 & 0 \\
\hline \multirow{4}{*}{$\begin{array}{l}\text { Unirea } \\
\text { Urziceni }\end{array}$} & \multirow[t]{4}{*}{1} & Maximum & 637 & 21 & 120 & 60 & 6 \\
\hline & & Minimum & 637 & 21 & 120 & 60 & 6 \\
\hline & & Average & 637 & 21 & 120 & 60 & 6 \\
\hline & & Std. Dev. & 0 & 0 & 0 & 0 & 0 \\
\hline \multirow[t]{4}{*}{ Valencia } & \multirow[t]{4}{*}{4} & Maximum & 1,190 & 30 & 247 & 129 & 10 \\
\hline & & Minimum & 680 & 20 & 145 & 55 & 6 \\
\hline & & Average & 909.25 & 24.75 & 202.25 & 93.00 & 7.50 \\
\hline & & Std. Dev. & 209.54 & 3.70 & 42.84 & 33.70 & 1.66 \\
\hline \multirow{4}{*}{$\begin{array}{l}\text { VfB } \\
\text { Stuttgart }\end{array}$} & \multirow[t]{4}{*}{1} & Maximum & 804 & 21 & 221 & 118 & 8 \\
\hline & & Minimum & 804 & 21 & 221 & 118 & 8 \\
\hline & & Average & 804 & 21 & 221 & 118 & 8 \\
\hline & & Std. Dev. & 0 & 0 & 0 & 0 & 0 \\
\hline \multirow[t]{4}{*}{ Villarreal } & \multirow[t]{4}{*}{2} & Maximum & 1,365 & 24 & 304 & 142 & 12 \\
\hline & & Minimum & 1,142 & 22 & 270 & 127 & 10 \\
\hline & & Average & $1,253.50$ & 23.00 & 287.00 & 134.50 & 11.00 \\
\hline & & Std. Dev. & 111.50 & 1.00 & 17.00 & 7.50 & 1.00 \\
\hline \multirow{4}{*}{$\begin{array}{l}\text { Werder } \\
\text { Bremen }\end{array}$} & \multirow[t]{4}{*}{6} & Maximum & 970 & 22 & 220 & 150 & 8 \\
\hline & & Minimum & 715 & 18 & 141 & 92 & 6 \\
\hline & & Average & 807.67 & 20.33 & 172.33 & 116.67 & 6.67 \\
\hline & & Std. Dev. & 89.91 & 1.25 & 27.60 & 22.51 & 0.94 \\
\hline \multirow[t]{4}{*}{ Wolfsburgo } & \multirow[t]{4}{*}{1} & Maximum & 662 & 17 & 141 & 87 & 6 \\
\hline & & Minimum & 662 & 17 & 141 & 87 & 6 \\
\hline & & Average & 662 & 17 & 141 & 87 & 6 \\
\hline & & Std. Dev. & 0 & 0 & 0 & 0 & 0 \\
\hline \multirow{4}{*}{$\begin{array}{l}\text { Zenit St. } \\
\text { Petersburgo }\end{array}$} & \multirow[t]{4}{*}{1} & Maximum & 759 & 17 & 162 & 77 & 6 \\
\hline & & Minimum & 759 & 17 & 162 & 77 & 6 \\
\hline & & Average & 759 & 17 & 162 & 77 & 6 \\
\hline & & Std. Dev. & 0 & 0 & 0 & 0 & 0 \\
\hline \multirow[t]{4}{*}{ Zurich } & \multirow[t]{4}{*}{1} & Maximum & 626 & 19 & 126 & 47 & 6 \\
\hline & & Minimum & 626 & 19 & 126 & 47 & 6 \\
\hline & & Average & 626 & 19 & 126 & 47 & 6 \\
\hline & & Std. Dev. & 0 & 0 & 0 & 0 & 0 \\
\hline
\end{tabular}




\section{References}

Blass AA (1992) Does the baseball labor market contradict the human capital model of investment? The Review of Economics and Statistics 74(2): 261-268.

Border KC (2004) On the Cobb-Douglas production function: 1-2. Retrieved from http://goo.gl/9wwG8H.

Bosca JE, Liern V, Martinez A, Sala R (2009) Increasing offensive or defensive efficiency? An analysis of Italian and Spanish football. Omega 37(1): 63-78.

Carmichael F, Thomas D (1995) Production and efficiency in team sports: an investigation of rugby league football. Applied Economics 27(9): 859-869.

Carmichael F, Thomas D, Ward R (2000) Team performance: the case of English premiership football. Managerial and Decision Economics 21(1): 31-45.

Caves D, Christensen L, Diewert WR (1982) The economic theory of index numbers and the measurement of input, output and productivity. Econometrica 50(6): 1393-1414.

Chiavenato I (1999) Introducción a la Teoría General de la Administración [Introduction to General Management Theory] $\left(5^{\text {th }}\right.$ ed). New York: McGraw Hill.

Dawson P, Dobson S, Gerrard B (2000) Estimating coaching efficiency in professional team sports: evidence from English association football. Scottish Journal of Political Economy 47(4): 399-421.

Douvis I, Pestana-Barros C (2008) Comparative analysis of football efficiency among two small European countries: Portugal and Greece. Sport Management International Journal 4(1): 5-29.

Espitia-Escuer M, Garcia-Cebrian LI (2008) Measuring the productivity of Spanish first division soccer teams. European Sport Management Quarterly 8(2): 229240.

Farrell MJ (1957) The Measurement of Productive Efficiency. Journal of the Royal Statistical Society 120(Part III): 253-281.

Fort R (2006) Sports Economics. Upper Saddle River: Prentice Hall.

Fort R, Quirk J (1995) Cross-subsidisation, incentives, and outcomes in professional sports leagues. Journal of Economic Literature 33(3): 1265-1299.

Garcia del Barrio P, Szymanski S (2009) Goal! Profit maximization versus win maximization in football. Review of Industrial Organization 34(1): 45-68.

Golany B, Roll Y (1989) An application procedure for DEA. Omega 17(3): 237-250.

Gonzalez-Gomez F, Picazo-Tadeo AJ (2010) Can we be satisfied with our football team? Evidence from Spanish professional football. Journal of Sports Economics 11(4): 418-442.

Grosskopf S (1993) Efficiency and productivity. In HO Fried, CAK Lovell, SS Schmidt (Eds.), The Measurement of Productive Efficiency: 160-194. New York: Oxford University Press.

Guzman I (2006) Measuring efficiency and sustainable growth in Spanish football teams. European Sport Management Quarterly 6(3): 267-287.

Guzman I, Morrow S (2007) Measuring efficiency and productivity in professional football teams: evidence from the English premier league. Central European Journal of Operations Research 15(4): 309-328.

Haas DJ (2003a) Productive efficiency of English football teams - a data envelopment analysis approach. Managerial and Decision Economics 24(5): 403-410.

Haas DJ (2003b) Technical efficiency in the major league soccer. Journal of Sports Economics 4(3): 203-215. 
Haas DJ, Kocher MG, Sutter M (2004) Measuring efficiency of German football teams by data envelopment analysis. Central European Journal of Operations Research 12(3): 251-268.

Jardin M (2010) Efficiency of French football clubs and its dynamics. MPRA Paper 19828.

Késenne, S (2007): The Economic Theory of Professional Sport: An Analytical Treatment. Cheltenham, UK and Northampton, USA: Edward Elgar Publishing.

Leibenstein H (1962) Allocative efficiency vs. X-efficiency. American Economic Review LVI(3): 392-415.

Mazur MJ (1994) Evaluating the relative efficiency of baseball players. In A Charnes, WW Cooper, AY Lewin, LM Seiford (Eds.), Data Envelopment Analysis: Theory, Methodology and Application. Norwell, MA, USA: Kluwer Academic Publishers.

Pestana Barros C, Couto E, Samagaio A (2014) Management ability, strategy, tactics and team performance. In J Goddard, P Sloane (Eds.), Handbook on the Economics of Professional Football. Cheltenham, UK and Northampton, USA: Edward Elgar Publishing.

Sandy R, Sloane P, Rosentraub MS (2004) The Economics of Sport: An International Perspective. New York: Palgrave MacMillan.

Schofield JA (1988) Production functions in the sports industry: an empirical analysis of professional cricket. Applied Economics 20(2): 177-193.

Sexton TR, Silkman RH, Hogan AJ (1986) Data envelopment analysis: critique and extensions. In RH Silkman (Eds.), Measuring Efficiency: An Assessment of Data Envelopment Analysis: 73-105. San Francisco: Jossey-Bass.

Szymanski S (1998) Why is Manchester United so successful? Business Strategy Review 9(4): 47-54.

Szymanski S (2003) The economic design of sporting contests. Journal of Economic Literature 41(4): 1137-1187.

Thiry B, Tulkens H (1989) Productivity, efficiency and technical progress, concepts and measurement. Annals of Public and Cooperative Economics 60(1): 9-41. 
